\begin{tabular}{|c|c|c|c|c|c|}
\hline MUNIBE Antropologia-Arkeologia & $n^{\circ} 65$ & $137-156$ & DONOSTIA & 2014 & ISSN 1132-2217 • eISSN 2172-4555 \\
\hline
\end{tabular}

\title{
Aproximación al uso ritual de las cuevas en la Edad del Hierro: el caso del Cantábrico Centro-Oriental (Península Ibérica)
}

\author{
A new approach to the ritual usage of caves during Iron Age: \\ The case of the Central-Eastern Cantabric (Iberian Peninsula)
}

KEY WORDS: Religion, caverns, deposits, sanctuary, Late Prehistory, Protohistory.

PALABRAS CLAVES: Religión, grutas, depósitos, santuario, Late Prehistory, Protohistoria.

GAKO-HITZAK: Erlijioa, haitzulo, depositoak, santutegia, Late Prehistory, Protohistoria.

Susana de LUÍS MARIÑO(1)

\begin{abstract}
Caves are, seemingly, the most well known Iron Age place of ritual of the Central-Eastern Cantabric. However, seldom studies analyse the religious phenomena that take place inside them, as research has traditionally focused on their funerary use. This article analyses, from an archaeological viewpoint, the different findings discovered at the caves, and suggests new interpretations, analysing the findings and drawing comparisons with other caves of nearby areas of Western Europe. It also takes into account several other aspects as the caves' formal characteristics, the distribution of the findings, evidences of the use of fire, as well as the typology of its deposits.
\end{abstract}

\section{RESUMEN}

La cueva es el lugar ritual aparentemente mejor conocido de la Edad del Hierro del Cantábrico Centro-oriental. Sin embargo, faltan estudios que analicen los fenómenos religiosos desarrollados en ellas, ya que la investigación tradicional se ha centrado en su función sepulcral. En esta aproximación se realiza un estudio desde el punto de vista arqueológico que propone nuevas interpretaciones a través del análisis de los hallazgos localizados en su interior y de puntuales comparaciones con otras cuevas de zonas aledañas y del occidente europeo. Además se tienen en cuenta otros aspectos como las características formales de la cueva, la distribución de los hallazgos en su interior, las evidencias del uso del fuego, así como la tipología de sus depósitos.

\section{LABURPENA}

Haitzuloa, antza, ba omen da hoberen ezagutzen den Burdin Aroko errito-toki ezagunena Erdialde-ekialdeko kantauriarra. Hala ere, horietan emandako fenomeno erlijiosoak aztertzen dituzten ikerketak falta dira. Horren arrazoia da ikerkuntza tradizionalak arreta jarri duela euren hileta-funtzioan. Honako hurbilketan, haitzuloen ikerketa egiten da arkeologiaren ikuspuntutik. Interpretazio berriak proposatzen dira haitzuloen barruan topatutako aztarnetatik abiatuta, baita hurbileko eskualdetan dauden haitzuloekin zein Europako mendebaldeko beste haitzuloekin egindako konparaketa puntualetatik abiatuta. Horiez gain, kontuan hartzen dira honako ikerketan bestelako datuak, hala nola haitzuloaren ezaugarri formalak, aurkikuntzen sakabanaketa haitzuloaren barruan, suaren erabilpenaren aztarnak edota euren deposituen tipologia.

\section{1.- INTRODUCCIÓN}

Es importante considerar la elección de la cueva como espacio ritual. Sus condiciones naturales la sitúan como lugar liminar (ALFAYÉ Y RODRIGUEZ-CORRAL: 2009: 107), un espacio "desde el cual se accede a una geografía sensitiva extrema, a un mundo fenomenológico radicalmente diferenciado del ordinario" (ALFAYÉ, 2009: 31) que propicia un ambiente sacro en su interior. Séneca ya señaló que la cueva era el lugar sagrado por antonomasia (Epist. IV, 12, 41, 3), algo que apoya la existencia de este arquetipo desde la Prehistoria hasta la actualidad.
Se conformaría entonces como nemeton, es decir, como el lugar de la naturaleza en el que se manifiesta la divinidad y que, debido a su "sacralidad inmanente", no precisa modificación alguna del espacio (SOPEÑA, 1987: 55-56; TORRES, 2010: 697; 2011: 447). Son por tanto santuarios naturales que se conocerán únicamente a través de las ofrendas depositadas en ellos (VIDAL et alii, 2000: 65). La delimitación de este espacio encuentra en la boca de la cueva el límite material e ideal entre el mundo terrenal y el mundo sobrenatural, un umbral físico que supone la agregación a un mundo nuevo cuando se traspasa. Traspasar el umbral ha sido relacionado con la celebración de ritua-

\footnotetext{
(1) Departamento de Prehistoria, Universidad Complutense de Madrid (UCM), Proyecto "Monte Bernorio en su Entorno" www.montebernorio.com - Instituto Monte Bernorio de Estudios de la Antigüedad del Cantábrico (IMBEAC) www.imbeac.com . Colectivo para la Ampliación de Estudios de la Arqueología Prehistórica (C.A.E.A.P). Departamento de Prehistoria. Facultad de Geografía e Historia. Avda. Profesor Aranguren SN. Universidad Complutense. 28040 MADRID. susanadeluismarino@gmail.com http://ucm.academia.edu/SusanadeLuisMari\%C3\%B10.
} 
les de paso de diversos ámbitos, entre los que destacan los funerarios y los relacionados con el paso a la vida adulta (VAN GENNEP, 1969: 35-37; GRAU, 2000: 217, GONZÁLEZ-ALCALDE, 2009: 96). Pomponio Mela (De Chorographia, III, 2,19) hace mención a cómo los druidas "enseñan muchas cosas [a los jóvenes/los más nobles de raza] realizando encuentros en sitios aislados y remotos durante veinte años, ya se tratara de una cueva o de arboledas apartadas" (GREEN, 1997: 48; ARCELIN ET BRUNAUX, 2003: 173). Del mismo modo que otros lugares de la naturaleza tales como el bosque, la cima de la montaña o los ríos, para los pueblos del ámbito cultural indoeuropeo todos ellos son lugares de encuentro entre el ser humano y lo divino. Este pasaje indica además como las cavernas, asimiladas con el vientre materno, son propicias para la celebración de ceremonias iniciáticas como las propias de las fratrías guerreras, de edad, sacerdotales o espirituales, pues ellas propician un renacimiento del iniciado (VAN GENNEP, 1969; GONZÁLEZ-ALCALDE, 1993: 74; 2006; 2009: 97). Todo indica que, en este tipo de rituales, la muerte, la iniciación, la identidad étnica y la relación con la divinidad para propiciar sus favores mantienen una relación holística en el contexto subterráneo (GONZÁLEZ-ALCALDE Y CHAPA, 1993: 170).

Existen dos tipos de ofrendas o sacrificios. Por un lado los cruentos, que implican el derramamiento de sangre o la interrupción de una vida, pudiendo ser las vícti- mas tanto animales como humanas. El sacrificio animal puede ser compartido por los humanos con la divinidad, o ser completamente entregado a ésta (TORRES, 2011: 484). El sacrificio puede ser augural o de vaticinio, funerario, de cautivos de guerra o hasta ejecuciones rituales de criminales, tipologías que conocemos dentro del ámbito cultural céltico por autores como Estrabón (Geogr. 3, 3, 7), Tito Livio (Perich. XLIX), Plinio (H. Nat. XXX, 12), César (B.G. VI, 17) o Diodoro (V, 32). Por otro lado existen los sacrificios no cruentos, apareciendo restos tanto de elementos orgánicos (plantas, alimentos, líquidos...) como inorgánicos (objetos de cerámica, metal, piedra...). A menudo estos últimos son sometidos a una "inutilización ritual" (que imposibilita la continuidad de su uso en el mundo terrenal) para asegurar su llegada al ámbito divino y permitir su consagración. Para ello se emplean acciones tales como la ruptura del objeto (común para el caso de las cerámicas), su desmontaje en piezas (como ocurrió con el casco de la cueva des Perrats en Francia), su deformación (común para los objetos metálicos) o su transformación a través del fuego (Fig.1) (GARCÍA, 1993: 55,298; ARCELIN Y BRUNAUX, 2003: 112; DUCONGÉ Y GÓMEZ DE SOTO, 2007: 480-486; CABRERA, 2010: 49). $\mathrm{S}$. Alfayé incluye otros tipos como la perforación de objetos o el recorte de objetos cerámicos, en concreto de "cabecitas humanas" (ALFAYÉ, 2011: 138-149).

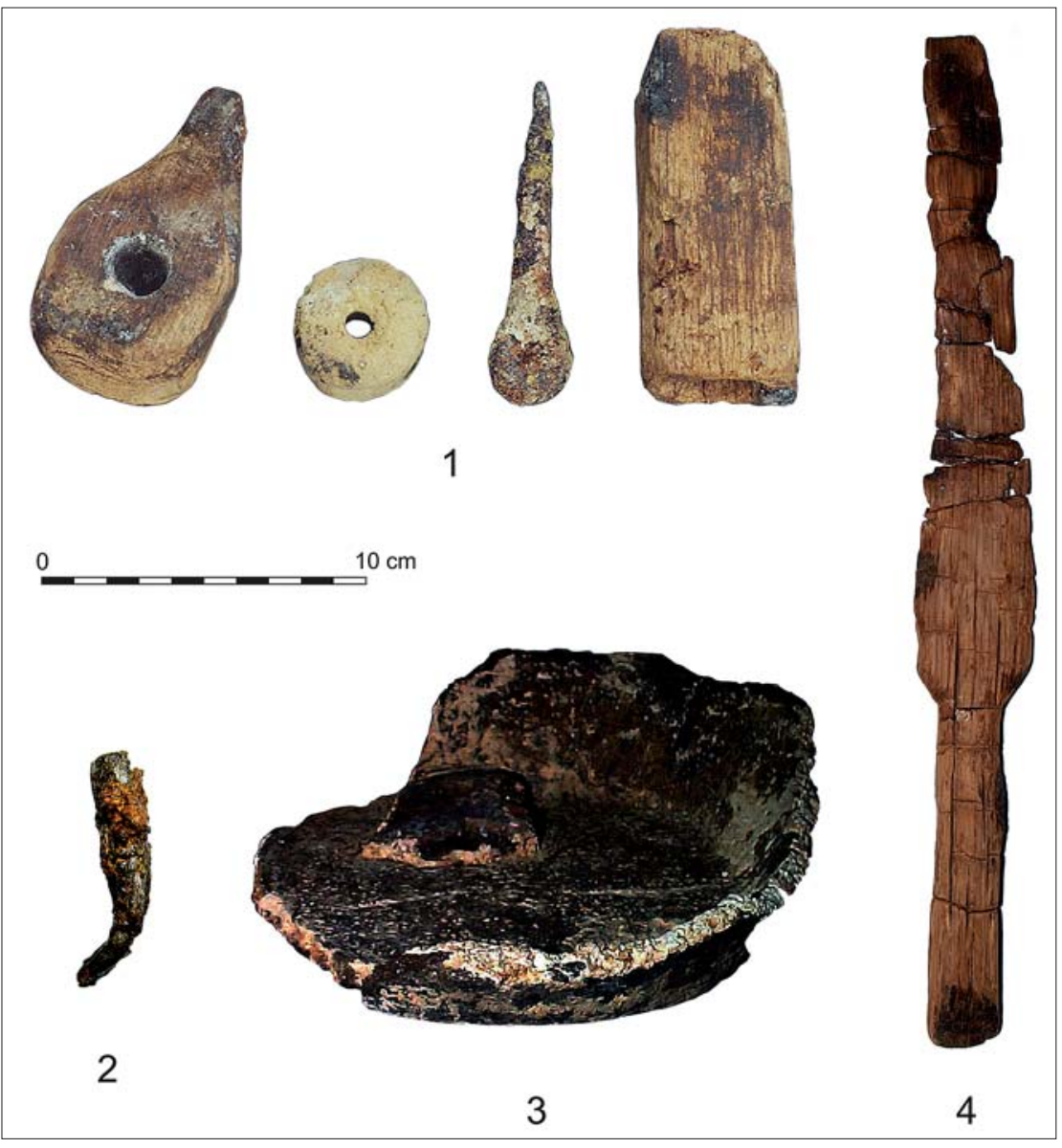

Fig. 1. Tipos de inutilización ritual realizados en objetos localizados en cuevas rituales de la Edad del Hierro en el Cantábrico central. N ${ }^{0}$ : Inutilización mediante desmontado de piezas que podrían formar parte de una misma estructura u objeto. Cueva del Aspio, (Smith y Muñoz 2010: 685). No2: Por deformación. Regatón de la cueva de Cofresnedo (Matienzo, Ruesga, Cantabria) (fotografía cedida por el MUPAC). №3: Por fractura. Vasija cerámica localizada en la "sala del lago" de la cueva de Cofresnedo (Matienzo, Ruesga, Cantabria) (cedida por el proyecto "La Prehistoria Reciente de Matienzo"). No 4: Por exposición al fuego, en la pieza espatiforme de la cueva del Aspio (fotografía cedida por el MUPAC). / Examples of disablement of artifacts found at Iron Age ritual caves from the Central Cantabric. No 1: Disablement by dismantling pieces that could be part of the same structure or object. Aspio Cave(Smith \& Muñoz 2010: 685). No 2: Deformation. Ferrule from Cofresnedo Cave (Matienzo, Ruesga, Cantabria) (image courtesy of the MUPAC). No3: Fracture. Pottery vessel found at the "lake room" of Cofresnedo Cave (Matienzo, Ruesga, Cantabria) (image courtesy of the project "La Prehistoria Reciente de Matienzo"). No 4: By fire exposure. Spathe-shaped artifact from Aspio Cave (image courtesy of the MUPAC). 
Los dos tipos de sacrificios pueden realizarse de manera individual o colectiva. Estos últimos son realizados por un conjunto de personas al que une algún tipo de vínculo (familiar, económico, étnico...), creando así una unión entre los oferentes y posibilitando la oferta de un don de mayor entidad a la divinidad (ARDĖVOL Y MUNILLA, 2003: 185186,189; CABRERA, 2010: 32; TORRES, 2011: 483-484).

\section{2.- ELECCIÓN DE LAS CUEVAS INCLUIDAS EN EL ESTUDIO. METODOLOGÍA Y PROBLEMÁTICA}

El territorio escogido para el desarrollo de este trabajo se sitúa en la vertiente cantábrica de la Península Ibérica. Esta vasta región se conformó en época prerromana como una unidad geográfico-cultural ya que Estrabón en su obra Geografía (III, 3, 7) denomina como "montañeses" a "los que jalonan el flanco norte de iberia: calaicos, astures y cántabros hasta llegar a los vascones y el Pirene, pues el modo de vida de todos ellos es semejante". Además, se conforma como unidad geográfica debido a sus condiciones climático-ambientales y su orografía abrupta.

Su zona centro-oriental cuenta con unos importantes sistemas kársticos, enclavándose la mayoría de ellos en la actual Comunidad Autónoma de Cantabria (FERNÁNDEZ, 1984: 12; PUNCH, 1998: 16-17; LEÓN, 1997: 720). Por este motivo, las cuevas incluidas en el presente estudio pertenecen en su mayoría a esta Comunidad, siendo comparadas y completadas con información referente a otros yacimientos subterráneos. La razón para ello está en buscar una contextualización más amplia del estudio, puesto que se entiende que no se trata de una zona aislada de su entorno y que los datos de aquellas áreas pueden aportar información útil al estudio. Entre ellos se encuentran los situados en Burgos, Palencia y León, en la Meseta Norte, así como en el País Vasco actual, con Bizkaia y Gipuzkoa en el Cantábrico Oriental y Álava en el Alto Valle del Ebro, contando con un caso puntual en Navarra (Fig.2). El Norte de Burgos, Norte de Palencia y zona Nororiental de León, formó parte del territorio de los cántabros en época histórica, lo que los vincula arqueológica y culturalmente. Para el caso del País Vasco, los datos de algunas cuevas se muestran muy similares a los recogidos en la zona de estudio, de tal forma que se consideran también una aportación útil que debe considerarse. Por último, la información se completa con referencias a algunas de las cuevas rituales del resto de la Europa del ámbito cultural céltico, puesto que son yacimientos que han aportado evidencias claras sobre un uso ritual y que pueden tomarse como referencia a la hora de ofrecer nuevas interpretaciones.

En cuanto a la elección de los yacimientos, se han descartado aquellos cuyos materiales no eran atribuibles cronológicamente a la Edad del Hierro, así como los que poseen únicamente arte esquemático-abstracto, ya que este fenómeno debe avanzar en sus estudios. Se incluyen los yacimientos cuyos materiales se han identificado como pertenecientes a la Edad del Hierro, diferenciando entre los que son con seguridad de esta época, y aquellos "dudosos" que deben ser revisados. Además tam- bién se incluyen algunas cuevas con restos romanos que parecen evidenciar un culto y/o ritual adscrito al mundo cultural prerromano

En cuanto a su determinación como "lugar ritual" se han tenido en cuenta varios criterios que, en muchas ocasiones, se dan a la vez en el mismo yacimiento. Por un lado su inhabitabilidad, que incluye características como el difícil acceso a la gruta, unas condiciones geológicas que lo impiden o la profundidad a la que se encuentran los materiales. Por otro lado debido a los restos encontrados en ellas, tanto por su misma naturaleza (por ejemplo, el hecho de encontrar una serie de materiales comunes en las necrópolis en el caso de Cofresnedo, Cantabria) (RUIZ Y SMITH, 2001; 2003: 163; HIERRO, 2002: 113) como por el contexto arqueológico en el que se localizan (por ejemplo el abrigo del Puyo, Cantabria, con túmulos y hogueras bajo ellos) (SAN MIGUEL et alii, 1991; FERNANDEZ, 2010). Estos dos criterios son determinantes para indicar que se trata de un lugar ritual, sobre todo en el caso de encontrar restos óseos humanos o materiales arqueológicos muy característicos de contextos rituales. También se incluyen los yacimientos que han sido estudiados y que no han sido vinculados con un uso funcional. En algunos casos, su sentido ritual es difícil de demostrar, pero no por ello esta opción debe ser descartada. Si los restos localizados en estas grutas se identifican como "rituales", éstos deben entenderse como muestra de la ceremonia llevada a cabo, o como depósitos u ofrendas destinadas al difunto, como se ha propuesto hasta ahora, o a la divinidad. La lista de los yacimientos incluidos aparece en la tabla anexa (Tabla I) y su distribución, en un mapa (Fig 2).

La investigación realizada se ha basado en una revisión de las fuentes bibliográficas existentes hasta el momento atendiendo a los datos arqueológicos que contienen. Gracias a ella se ha elaborado una base de datos incluyendo unas variables importantes desde el punto de vista de la arqueología del ritual. El resumen del resultado de algunas variables se muestra en la tabla anexa (Tabla I), mientras que las conclusiones extraídas de la recopilación y estudio de estos datos se comentan a lo largo de este artículo.

No obstante, hay que hacer mención a la problemática que presenta este tipo de estudio y a la cautela con la que hay que analizar los datos.

En primer lugar, la mayoría de los objetos arqueológicos proceden de un nivel superficial, por lo que pueden haberse localizado en una posición secundaria. Según este hecho, pueden aparecer vinculados accidentalmente a materiales de otras épocas, sobre todo a aquellos a los que no se les puede atribuir una cronología tipológica como puede ser la fauna o los carbones y hogueras. No obstante, esta vinculación también pudo ser intencionada, estando motivada por razones simbólicas, como puede haberse dado en la cueva de Cofresnedo (Cantabria) (RUIZ Y SMITH, 2001; 2003: 163; HIERRO, 2002: 113). Este hecho ha sido identificado en otros casos arqueológicos, y es lo que S. Alfayé ha denominado "reciclaje sim- 


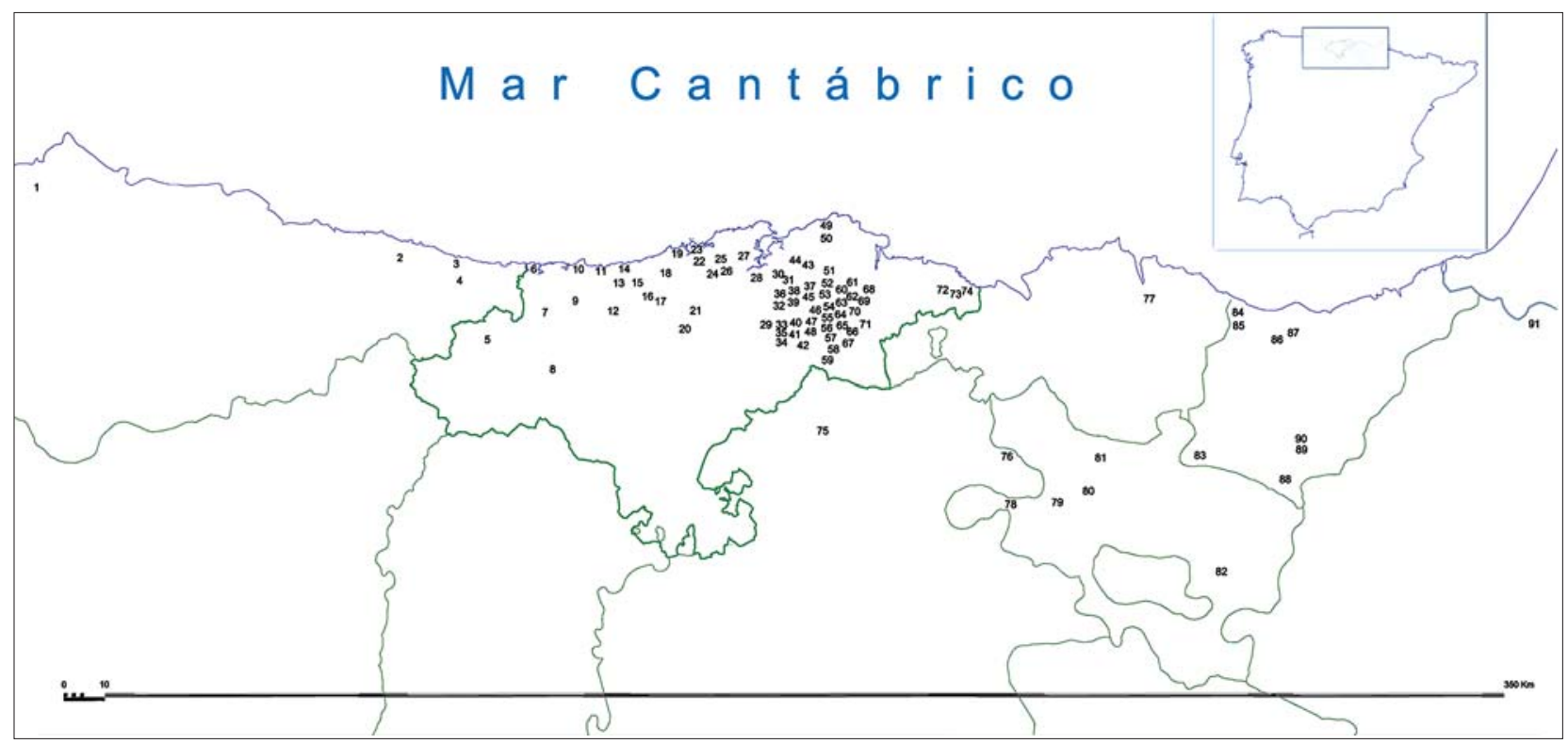

Fig. 2. Localización de las cuevas rituales de la Edad del Hierro incluidas en este estudio. La relación número-nombre de cueva se especifica en la tabla I. Location of the Iron Age ritual caves included in this study. The number-cave name correlation is detailed in table I.

bólico" (ALFAYÉ, 2011: 162-169). En este estudio se asumen como parte del mismo depósito los materiales que se han localizado juntos o muy próximos, a la espera de análisis más exhaustivos que puedan indicar lo contrario.

En segundo lugar, muchos de los hallazgos se han realizado como parte de exploraciones espeleológicas o en campañas de intervención arqueológica interesadas en cronologías más antiguas, por lo que la descripción de los hallazgos protohistóricos es insuficiente, pudiendo tratarse de materiales de otras épocas. En este sentido, en la tabla adjunta se incluye la categoría "dudosa".

En tercer lugar, son muchos los casos que no han propuesto hipótesis atendiendo al contexto arqueológico de los restos. En este estudio se han rescatado este tipo de indicaciones para ayudar a la interpretación de los materiales.

Es necesaria, por tanto, una revisión de la mayoría de las piezas y los yacimientos que aquí se presentan, así como de otros estudios más específicos como dataciones, análisis de pastas y exámenes tipológicos. Toda esta problemática se tiene en cuenta a la hora de desarrollar las hipótesis que se describen a continuación. Por este motivo este trabajo realiza a modo de estudio "aproximativo", un trabajo que sirva de base para estudios posteriores y otorgue interperaciones sobre la posible naturaleza ritual de sus restos.

\section{CARACTERÍSTICAS DE LAS GRUTAS}

Las cuevas con usos rituales en la Edad del Hierro en el Cantábrico Central se ubican de manera general en una posición dominante desde la que se controla visualmente el territorio. Su difícil accesibilidad, así como la imposibilidad de habitar en ellas, son características que reafirman su carácter ritual (PRADOS, 1994: 132; ARCELIN ET BRU-
NAUX, 2003). La mayoría de sus bocas son amplias (el Aspio, la Coventosa...) aunque existen aquellas que poseen un tamaño medio (Llusa, La Brazada...) e incluso pequeño (Callejonda, Saúco, La Graciosa I y II...). Las cuevas con bocas más grandes suelen tener un acceso complicado, mientras que las de boca más reducida son más accesibles pero se encuentran más escondidas en el paisaje (RUIZ Y MUÑOZ, 2013: 234). Su desarrollo también es variable, existiendo cuevas que llegan a tener 35 km de recorrido (como Coventosa), 23 km (Fresca) o 7,5 km (Linar), algunas entre los 3,5 y 1 km (Agua o del Molino, Rio Cueva u Hoyo de los Herreros), otras menos de $1 \mathrm{~km}$ (Cofresnedo, La Cuevona de Riclones, Sotarraña, Cobrante, Cofiar o Cuatribu), incluso inferiores a los $100 \mathrm{~m}$ (La Madrid, La Palenciana, Arín, Los Castros II), o de escaso recorrido (La Graciosa I y II, Reyes) (BERMEJO et alii, 1987; MORLOTE et alii, 1996). Esto puede hacernos considerar que el ritual desarrollado pudo cambiar sustancialmente dependiendo de estas características.

La presencia de agua (desde arroyos hasta goteos) en estas cuevas no es común, tratándose en su mayoría de cavidades secas. Algunas de ellas poseen ríos, pero estos no suelen relacionarse con los depósitos ya que se encuentran en alturas diferentes dentro de la misma cavidad. Existen varias excepciones como Cofresnedo, con un gran gour activo denominado "el lago", y el Puyo, un abrigo muy húmedo con constantes goteos (SMITH, 1985: 46; SAN MIGUEL et alii, 1991; RUIZ Y SMITH, 2003; FERNÁNDEZ, 2010).

En cuanto a las evidencias arqueológicas que contienen, algunas se han situado en la fase cronológica del Bronce Final- Hierro I, sobre todo en las cuevas de País Vasco así como en la de Fuentenegroso de Asturias (ALTUNA et alii, 1995; BARROSO et alii, 2007). Otras se sitúan 
en la Primera Edad del Hierro (SERNA, 1992: 262; MORLOTE et alii, 1996: 242-243; RUIZ VELEZ, 2009: 265; FERNÁNDEZ, 2010: 560) y otras en la Segunda Edad del Hierro (GÓMEZ 2003: 222,225,227-228; SERNA, 1992: 262; MORLOTE et alii, 1996: 221-222). Sin embargo, en la mayoría de los casos su cronología exacta no se precisa (Tabla I).

Un importante porcentaje de ellas contienen restos humanos, razón por la cual los investigadores les han atribuido un carácter sepulcral. No obstante, se ha llegado a otorgar el mismo sentido aunque no contengan este tipo de restos guiándose, en varias ocasiones, por la tipología cerámica que contienen (MUÑOZ Y MALPELO, 1992; MORLOTE et alii, 1996; MUÑOZ, 1996: 100-101, PERALTA, 2003: 64-77). También se indicó que podría existir una relación entre los depósitos de materiales de la Edad del Hierro y el arte esquemático-abstracto, ambos con una posible función sepulcral (MUÑOZ et alii, 1992; MORLOTE et alii, 1996; SMITH, 1996B; SERNA et alii, 1996). No obstante los que defendieron inicialmente esta tesis se mantienen cautos en la actualidad a la vista de los nuevos estudios sobre este tipo de expresión artístico-ritual (GARCÍA Y GONZÁLEZ, 2003; GÓMEZ, 2003; LLANOS, 2003). De las cavidades estudiadas, una mayoría posee este tipo de pintura rupestre, por lo que aunque los materiales y las manifestaciones artísticas no sean coetáneas, es posible que exista una relación entre ellos, pues pudieron tener preferencia los lugares con evidencias de tiempos ante- riores para realizar las marcas. La presencia de fauna, hogueras y suelo carbonoso en el interior de las cuevas con depósito es también bastante común, por lo que parece que desempeñaron una importante función en el ritual.

Los pueblos de cultura céltica apenas acondicionaban sus lugares rituales ya que habitualmente elegían sitios con una "sacralidad inmanente" que lo hacía innecesario. No obstante, en las cuevas se han localizado estructuras que, en cierta medida, suponen una modificación del espacio. Por un lado se sitúan las "cubetas" u "hoyos" realizados en los suelos de la cueva. Se trata de pequeños gours que han sido excavados para darles forma o hacerlos más profundos y en los que se han localizado restos de carbones y materiales arqueológicos (Fig. 3) (SMITH Y MUÑOZ, 1984: 131; MUÑOZ et alii, 1992: 310; GÓMEZ, 2003: 223-224; SMITH et alii, e.p.).

Por otro lado, en la cueva de Cofiar o los Trillos (Cantabria) se han localizado dos zócalos de piedra de forma circular y una grieta colmatada intencionalmente en la zona donde aparecieron los materiales arqueológicos (BOHIGAS et alii, 1992: 233). En El Puyo (Cantabria) parece que, además de los 23 túmulos, existieron diversas estructuras como unos muros a modo de delimitación exterior, cinco recintos de distintas características adosados contra la pared del abrigo y un pequeño murete adosado a la gran piedra central a modo de banco corrido (Fig. 4) (FERNÁNDEZ, 2010).

\begin{tabular}{|c|c|c|c|c|c|c|c|c|c|c|c|c|}
\hline $\mathrm{N}^{\circ} \mathrm{M}$ & CUEVA & LOCALIZACIÓN & CRONOLOG & E.A & R.H & FA & CE & $\mathbf{M}$ & ESTRUC & $\mathbf{H}$ & C & OTROS \\
\hline \multicolumn{13}{|c|}{ CANTABRIA } \\
\hline 39 & Acebo & Mortesante (Miera) & Hierro II (D) & & & & & & & & & \\
\hline 55 & Agua o del Molino & (Matienzo, Ruesga) & Hierro II & & & & & & & & & \\
\hline 67 & Aguila o Peña Sota III & (Asón, Soba) & E. del Hierro & & & & & & & & & \\
\hline 49 & Arín & (Ajo, Bareyo) & E. del Hierro & & & & & & & & & \\
\hline 71 & Aspio & (Valle, Ruesga) & Hierro II & & & & & & & & & $\begin{array}{c}\text { Madera, } \\
\text { malacofauna }\end{array}$ \\
\hline 46 & Barandas & (Mienzo, Ruega) & Hierro I & & & & & & Cubetas & & & \\
\hline 10 & Barcenal II & La Revilla (San Vicente de la Barquera) & Hierro II (D) & & & & & & & & & \\
\hline 25 & Calero II & Barcenillas (Piélagos) & E. del Hierro & & & & & & Cubetas, muro & & & Malacofauna \\
\hline 20 & Callejonda & Tarriba (San Felices de Buelna) & Hierro II & & & & & & & & & \\
\hline 62 & Cantal & (San Bartolomé de los Montes, Voto) & E. del Hierro (D) & & & & & & & & & \\
\hline 23 & Carabias & Carabias (Miengo) & E. del Hierro & & & & & & & & & \\
\hline 32 & Cigudal & Mortesante (Miera) & Hierro II & & & & & & & & & Lítico \\
\hline 69 & Cobrante & (Caburrao, Voto) & E. del Hierro & & & & & & & & & \\
\hline 66 & Cofiar o los Trillos & (Hoyo Masayo, Soba) & Hierro I & & & & & & $\begin{array}{c}\text { Zócalos, sellado } \\
\text { de grieta }\end{array}$ & & & Lítico \\
\hline 54 & Cofresnedo & (Matienzo, Ruesga) & Hierro II & & & & & & & & & $\begin{array}{l}\text { Pasta vítrea, } \\
\text { granos de } \\
\text { cereal, mimbre }\end{array}$ \\
\hline 72 & Covarrubias & (Los Corrales, Castro Urdiales) & E. del Hierro & & & & & & & & & \\
\hline 57 & Coventosa & (Val de Asón, Arredondo) & Hierro II & & & & & & Cubetas & & & Lítico \\
\hline 70 & Cuatribu & (Ruesga) & E. Hierro & & & & & & & & & \\
\hline 22 & Cudón & Cudón (Miengo) & E. Hierro & & & & & & Cubetas & & & Lítico \\
\hline 6 & Cueto o Lanzal & Pechón (Val de San Vicente) & Hierro II (D) & & & & & & & & & \\
\hline 12 & Cueto Ruvalle & Santibáñez (Cabezón de la Sal) & Hierro II (D) & & & & & & & & & \\
\hline 42 & Cueva Mora & Calseca (Ruesga) & E. Hierro (D) & & & & & & & & & Lítico \\
\hline 5 & de Covará & Allende (Castro Cillorigo) & Hierro II & & & & & & & & & Lítico \\
\hline 60 & de Reyes & (Matienzo, Ruesga) & E. Hierro & & & & & & & & & \\
\hline 27 & del Mapa o Angelita & Revilla (Camargo) & E. del Hierro & & & & & & & & & $\begin{array}{c}\text { Lítico, } \\
\text { malacofauna }\end{array}$ \\
\hline
\end{tabular}




\begin{tabular}{|c|c|c|c|c|c|c|c|c|c|c|c|}
\hline $\mathrm{N}^{\circ} \mathrm{M}$ & CUEVA & LOCALIZACIÓN & CRONOLOG & E.A & R.H & FA & CE & $\mathbf{M}$ & ESTRUC & \begin{tabular}{l|l} 
H & C \\
\end{tabular} & OTROS \\
\hline \multicolumn{12}{|c|}{ CANTABRIA } \\
\hline 47 & $\begin{array}{c}\text { Delante de la } \\
\text { cueva o del Masío }\end{array}$ & Bustablado (Arredondo) & E. del Hierro & & & & & & & & Lítico \\
\hline 38 & El Covarón & Mortesante (Miera) & Hierro II & & & & & & & & Lítico \\
\hline 11 & El Portillo IV & Casasola (Ruiloba) & E. del Hierro(D) & & & & & & & & $\begin{array}{c}\text { Lítico, } \\
\text { malacofauna }\end{array}$ \\
\hline 48 & Falso Escalón & (Val de Asón, Arredondo) & E. del Hierro & & & & & & & & Lítico \\
\hline 58 & Fresca & (Asón, Soba) & E. del Hierro & & & & & & & & \\
\hline 74 & $\begin{array}{l}\text { Grande o de } \\
\text { los Corrales }\end{array}$ & Los Corrales (Castro Urdiales) & E. del Hierro & & & & & & & & \\
\hline 17 & Gurugú II & Bedicó (Cartes) & Hierro II & & & & & & & & $\begin{array}{c}\text { Lítico, } \\
\text { malacofauna }\end{array}$ \\
\hline 16 & $\begin{array}{l}\text { Hoyo de los } \\
\text { Herreros }\end{array}$ & Barcenaciones (Reocín) & E. del Hierro & & & & & & Cubetas & & $\begin{array}{l}\text { Madera, lítico, } \\
\text { malacofauna }\end{array}$ \\
\hline 64 & La Brazada & (Riba, Ruesga) & E. del Hierro & & & & & & & & \\
\hline 53 & La Covarona & (Llueva, Voto) & E. del Hierro & & & & & & & & \\
\hline 7 & La Cuevona & Riclones (Río Nansa) & E. del Hierro (D) & & & & & & & & \\
\hline 64 & La Cuquisera & (Matienzo, Ruesga) & Hierro II & & & & & & Túmulo & & \\
\hline 9 & La Frontal (Superior) & La Concha (Valdáliga) & E. del Hierro (D) & & & & & & & & \\
\hline 31 & La Graciosa I & Rioz (Medio Cudeyo) & E. del Hierro & & & & & & & & \\
\hline 30 & La Graciosa II & Rioz (Medio Cudeyo) & E. del Hierro & & & & & & & & $\begin{array}{c}\text { Lítico, } \\
\text { malacofauna }\end{array}$ \\
\hline 35 & La Hazuca & Calseca (Ruesga) & E. del Hierro (D) & & & & & & & & \\
\hline 56 & La Llosa o La Arena & (Socueva, Arredondo) & E. del Hierro & & & & & & & & \\
\hline 50 & La Llusa & (Villanueva, Ribamontán al Monte) & E. del Hierro (D) & & & & & & & & \\
\hline 34 & La Palenciana & La Toba (Miera) & E. del Hierro & & & & & & & & Lítico \\
\hline 41 & La Puntida & Ajanedo (Miera) & E. del Hierro & & & & & & & & \\
\hline 18 & La Raposa & Vaspiéres (Santillana del Mar) & E. del Hierro & & & & & & & & \\
\hline 19 & La Tejera (o Las Brujas) & Ongayo (Suances) & E. del Hierro (D) & & & & & & & & Lítico \\
\hline 28 & La Tobalina & Cabárceno (Penagos) & E. del Hierro & & & & & & & & \\
\hline 37 & Lamadrid & (Rucandio, Riotuerto) & Hierro I & & & & & & & & $\begin{array}{l}\text { Lítico, } \\
\text { malacofauna }\end{array}$ \\
\hline 40 & Las Cabras o la Bona & Mirones (Miera) & E. del Hierro (D) & & & & & & & & \\
\hline 13 & Las Cáscaras & Canales (Udías) & Hierro II & & & & & & & & \\
\hline 24 & Las Cubrizas & Barcenillas (Piélagos) & E. del Hierro & & & & & & & & $\begin{array}{c}\text { Lítico, } \\
\text { malacofauna }\end{array}$ \\
\hline 21 & Las Monedas & Puente Viesgo & E. del Hierro (D) & & & & & & & & \\
\hline 15 & Linar & La Busta (Alfoz de Lloredo) & E. del Hierro (D) & & & & & & & & $\begin{array}{c}\text { Madera, } \\
\text { malacofauna }\end{array}$ \\
\hline 61 & Los Castros II & (El Castillo, Arnuero) & Hierro II & & & & & & & & \\
\hline 51 & Los Moros & (Garzón, Solórzano) & E. del Hierro (D) & & & & & & & & \\
\hline 59 & Los Santos & (Navajeda, Entrambasaguas) & E. del Hierro & & & & & & & & Lítico \\
\hline 36 & Maciu & Angustina (Riotuerto) & E. del Hierro (D) & & & & & & & & Lítico \\
\hline 26 & Portillo del Arenal & Velo (Piélagos) & E. del Hierro (D) & & & & & & & & \\
\hline 29 & Puyo & La Cárcoba (Miera) & Hierro I & & & & & & $\begin{array}{c}\text { Túmulos muros, } \\
\text { banco corrido, } \\
\text { zócalos }\end{array}$ & & $\begin{array}{c}\text { Lítico, } \\
\text { malacofauna }\end{array}$ \\
\hline 43 & Riocueva & Hoznayo (Entrambasaguas) & E. del Hierro (D) & & & & & & & & Lítico \\
\hline 44 & Riocueva II & Hoznayo (Entrambasaguas) & E. del Hierro (D) & & & & & & & & \\
\hline 52 & Ruchano & (Riaño, Solórzano) & Hierro II & & & & & & & & \\
\hline 45 & Salto del cabrito & (Riotuerto) & E. del Hierro & & & & & & & & \\
\hline 68 & Saúco (o del Chile) & (San Pantaleón de Aras, Voto) & E. del Hierro & & & & & & & & \\
\hline 33 & $\begin{array}{l}\text { Soterraña o de } \\
\text { Las Regadas }\end{array}$ & La Cárcoba (Miera) & Hierro II & & & & & & & & \\
\hline 8 & Tío Marcelino & Santotís (Tudanca) & E. del Hierro (D) & & & & & & Cubetas & & Madera \\
\hline 63 & Torca de la lanza & (Sel de Suto) & Hierro II & & & & & & & & \\
\hline 14 & Villegas II & Cóbreces & Hierro II (D) & & & & & & & & \\
\hline 73 & Ziguste & Los Corrales (Castro Urdiales) & Hierro II & & & & & & & & Malacofauna \\
\hline
\end{tabular}




\begin{tabular}{|c|c|c|c|c|c|c|c|c|c|c|c|c|}
\hline $\mathbf{N}^{\circ} \mathbf{M}$ & CUEVA & LOCALIZACIÓN & CRONOLOG & E.A & R.H & FA & CE & $M$ & ESTRUC & $\mathbf{H}$ & C & OTROS \\
\hline \multicolumn{13}{|c|}{ PAÍS VASCO } \\
\hline 81 & Lazaldai & Zárate & E. del Hierro (D) & & & & & & & & & \\
\hline 80 & Los Goros & Hueto Arriba & $\begin{array}{c}\text { Bronce } \\
\text { Final- Hierro I (D) }\end{array}$ & & & & & & & & & \\
\hline 78 & Peña Orao & Osma de Valdegobía & $\begin{array}{l}\text { Eneolítico-E. } \\
\text { del Hierro (D) }\end{array}$ & & & & & & & & & \\
\hline 82 & Peña Rasgada & Atauri & Hierro I y II & & & & & & & & & $\begin{array}{l}\text { Trigo calcinado } \\
\text { y bellotas, } \\
\text { cuentas de } \\
\text { calcita, lítico }\end{array}$ \\
\hline 79 & $\begin{array}{l}\text { Solacueva de } \\
\text { Lakozmonte }\end{array}$ & Jócano & E. del Hierro (D) & & & & & & $\begin{array}{l}\text { Limitado } \\
\text { por piedras }\end{array}$ & & & \\
\hline \multicolumn{13}{|c|}{ Guipúzcoa } \\
\hline 86 & Amalda & Zestoa & Hierro II & & & & & & & & & Lítico \\
\hline 88 & Antzuzkar & Parzonería de Altzania & $\begin{array}{c}\text { Bronce } \\
\text { Final- Hierro (D) }\end{array}$ & & & & & & & & & \\
\hline 85 & Arbil & Deba & $\begin{array}{c}\text { Bronce } \\
\text { Final- Hierro I (D) }\end{array}$ & & & & & & & & & \\
\hline 87 & Ekain V & Deba & $\begin{array}{c}\text { Bronce } \\
\text { Final- Hierro I (D) }\end{array}$ & & & & & & & & & \\
\hline 83 & Gazteluarro IV & Aretxabaleta & $\begin{array}{c}\text { Bronce } \\
\text { Final- Hierro I (D) }\end{array}$ & & & & & & & & & \\
\hline 84 & Kiputz II & Mutriku & $\begin{array}{c}\text { Bronce } \\
\text { Final- Hierro I (D) }\end{array}$ & & & & & & & & & \\
\hline 90 & Lokatza & Ataun & Hierro II & & & & & & & & & \\
\hline 89 & Usategi & Ataun & Hierro II & & & & & & & & & \\
\hline \multicolumn{13}{|c|}{ Vizcaya } \\
\hline 77 & Santimamiñe & Guernica & Hierro II (D) & & & & & & & & & $\begin{array}{l}\text { Pesa de telar, } \\
\text { aguja de sílex }\end{array}$ \\
\hline \multicolumn{13}{|c|}{ NAVARRA } \\
\hline 91 & Akelarren-Leze & Zugarramurdi & E. del Hierro (D) & & & & & & & & & \\
\hline \multicolumn{13}{|c|}{ ASTURIAS } \\
\hline 1 & El Hueso & Pillarno & E. del Hierro & & & & & & & & & \\
\hline 4 & Fuentenegroso & Fuentenegroso & $\begin{array}{c}\text { Bronce } \\
\text { Final- Hierro I }\end{array}$ & & & & & & & & & \\
\hline 3 & La Zurra & Purón, Llanes & Hierro II & & & & & & & & & \\
\hline 2 & $\begin{array}{l}\text { Pueblo Bajo } \\
\text { de Lledías }\end{array}$ & Llanes & E. del Hierro (D) & & & & & & & & & \\
\hline \multicolumn{13}{|c|}{ BURGOS } \\
\hline 75 & Ojo Guareña & Merindad de Sotoscueva & Hierro I & & & & & & $\begin{array}{c}\text { Depósito } \\
\text { para agua }\end{array}$ & & & \\
\hline 76 & El Puente & Orduña & Romana & & & & & & & & & Inscripciones \\
\hline
\end{tabular}

Tabla 1: Lista de cuevas incluidas en la investigación y relación de algunas de sus variables de estudio. Abreviaturas y correspondencias: $\mathbf{N}^{\circ} \mathbf{M}$ : Número en el mapa CRONOLOG: Cronología (D): Cronología dudosa E.A: Arte esquemático-abstracto R.H: Restos humanos FAU: Fauna CE: Cerámica M: Objetos de metal ESTRUC: Estructuras H: Hogueras C: Carbones.

\section{4.- LOCALIZACIÓN DE HALLAZGOS}

Los materiales arqueológicos de la Edad del Hierro estudiados han aparecido siempre en el interior de la cueva o sima, a excepción de los materiales del abrigo del Puyo, que aparecieron tanto en un nivel superficial como en el interior de los túmulos que alberga.

En lo referente a las cuevas, han sido diversos los lugares elegidos para depositar los restos. Aunque algunos se han hallado en los vestíbulos en situación de penumbra o semioscuridad (Coventosa, La Puntida, Las Regadas, El Covarón) (BERMEJO et alii, 1987: 180,237; MORLOTE et alii, 1996: 261,264; GÓMEZ, 2003: 225), en general se elige un lugar alejado de la entrada en la semioscuridad u oscuridad. La mayoría se sitúan en el interior, a unos 100-200 metros de la boca, pudiendo encontrarse tanto en amplias salas de techo elevado (La Palenciana, El Acebo, Maciu, Aspio...), como en salas de cruce de galerías (Lamadrid, La Tobalina,
El Cigudal, Peña Sota III... ) (SERNA et alii, 1994: 371; MORLOTE et alii, 1996: 202,259,272; MUÑOZY RUIZ, 2013: 233). El hecho de que los hallazgos aparezcan realmente alejados de la entrada, como por ejemplo el caso de las cerámicas de Cofresnedo en la "sala del lago" (400 metros al interior) (RUIZY SMITH, 2001: 168), son de por sí una buena razón para pensar en su sentido ritual pues su localización indica que no puede tener ningún sentido funcional.

En ocasiones se eligen elementos acuáticos para su deposición, ya sea en el interior de grandes gours en ocasiones activos (Cofresnedo), de pequeños gours activos o no (Linar, Cobrante, Cofiar, del Mapa), así como cerca de estos, de ríos o de surgencias de agua subterráneas (Ruchano) (MORLOTE et alii, 1996: 223,267,269; RUIZ Y SMITH, 2001: 168-169). En otros casos parece que se busca una ocultación, por lo que se depositan entre los bloques caídos de techo (Linar, Portillo del Arenal, Río- 

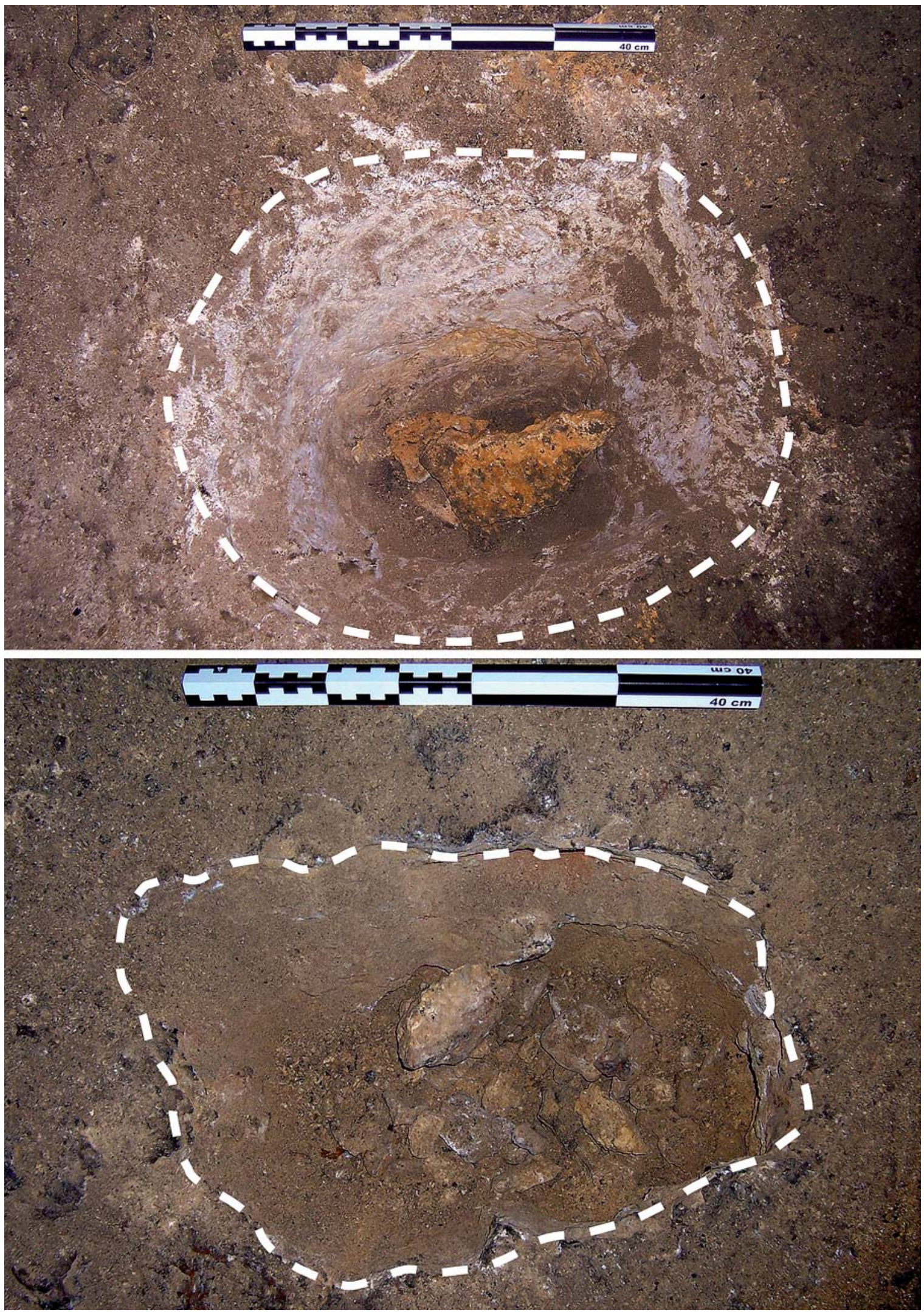

Fig. 3. Cubetas, "hoyos" o gours modificados antrópicamente de la cueva de La Coventosa (Val de Asón, Arredondo, Cantabria). Las líneas discontinuas indican el límite de ésta. (fotografía realizada por la autora. C.A.E.A.P.). / Trays, "holes" or anthropically modified rimstone dams from Coventosa Cave. (Val de Asón, Arredondo, Cantabria). The dotted lines indicate the limit of said cave (photograph taken by the author, C.A.E.A.P.). 
cueva, Barcenal II, Sotarraña, Aspio) así como en pequeñas aberturas en la roca (Cudón, Delante de la Cueva o el Masío, Cuatribu) o en lugares de difícil acceso (Cofresnedo) (RUIZY SMITH, 2001: 166-168). En otras ocasiones se busca justamente lo contrario, dejando el depósito en un lugar vistoso sobre coladas estalagmíticas como en las cuevas de Cudón, Cueva Mora, Águila o Peña Sota III, Coventosa, Calero II y La Cuquisera. También encima de bloques como en las cuevas del Saúco y Falso Escalón, así como en el centro de la sala, como en la cueva de la Fresca. En otras ocasiones parece que se elige un lugar discreto cercano a la pared (Aspio, Cantal, La Tobalina, Cobrante, La Llosa, de Reyes, Coventosa) o se coloca en la base de coladas estalagmíticas (Agua o del Molino). Otras veces se utiliza un sitio cercano a pozos o simas en el interior de la cueva (Coventosa, La Cuquisera o Codisera, La Brazada, Cofiar) (BOHIGAS et alii, 1992: 233; MORLOTE et alii, 1996: 175, 229-230, 241, 248, 251, 258, 268, 270-273; SMITH, 1996a: 175).

Muchos de los materiales se hallaron en relación a restos de hogueras (MUÑOZ et alii, 1992: 310-313; MORLOTE et alii, 1996: 242, 247-249, 254-257, 259, 263-265, 267, 269, 272-273; GÓMEZ, 2003: 223;) y/o vinculados a carbones (MUÑOZ et alii, 1992: 312; MORLOTE et alii, 1996: 231,258,261,265-266,268,270-271,273; GÓMEZ, 2003: 222-228) (Fig. 5).

Además, algunos materiales arqueológicos se localizaron próximos a restos de épocas pasadas, generalmente del Paleolítico o la Edad del Bronce, pudiendo ser esta vinculación accidental (al encontrarse en posición secundaria) o intencionada (posición primaria). En este último caso, la vinculación habría tenido, seguramente, una motivación simbólica.

\section{5.- CUEVAS CON RESTOS HUMANOS: USO FU- NERARIO, SACRIFICIOS HUMANOS Y RITUALES DE PASO}

La presencia de restos humanos en el interior de las cuevas, la mayoría con evidencias de haber sido expuestos al fuego, suscitan la formulación de varias hipótesis. Una de las posibilidades es que, como expone la interpretación tradicional, se trate de un uso funerario de las cavidades. Hay que tener en cuenta que serían casos diferenciados de los tradicionalmente practicados en ese momento en el resto de la Península Ibérica, que se dan en necrópolis. Existe un número escaso de ellas localizadas y excavadas en el Cantábrico (TORRES, 2011: 518-529), lo que ha llevado a plantear que las cuevas desempeñaran la misma función, o que el ritual funerario no dejara evidencias materiales como ocurriría con la exposición de cadáveres o la deposición del cuerpo en lugares acuáticos (RUIZY LORRIO, 1995:226-227). En este sentido, algunas de las cerámicas depositadas en las cuevas podrían haber servido de contenedores de los restos cremados, o de acompañamiento de éstos, tal y como se ha interpretado para las formas de "perfil en s" y para las vasijas de tipo "La Brazada" localizadas en las cuevas cántabras (MORLOTE et alii, 1996; SMITH et alii, e.p.), aunque no haya ninguna evidencia que lo demuestre. Esta hipótesis también se contempla para los restos localizados en la cueva asturiana de Pueblo Bajo de Lledías (Llanes) (MAYA 1989:82; FANJUL et alii, 2010:20) y para otras cuevas vascas como la de los Moros o Peña Rasgada (Atauri, Álava) (LLANOS Y AGORRETA, 1962), la cueva del Bortal (Vizcaya) (ARIAS Y ARMENDARIZ, 1998: 70) y la cueva de los Goros (Hueto Arriva, Álava) (LLANOS, 1991). Existen casos únicos como el de la cueva de Fuentenegroso (Asturias) en el que se ha localizado el enterramiento de una mujer con su cuerpo inhumado (BARROSO et alii, 2007), o el del abrigo tumular de El Puyo (Miera, Cantabria), interpretado como un lugar funerario (Fig. 4) (SAN MIGUEL et alii, 1991; FERNÁNDEZ, 2010; TORRES, 2010:711).

Por otro lado hay que indicar que algunos restos óseos han sido atribuidos a la Edad del Hierro por encontrarse cerca de materiales de esta cronología, pero cuyas dataciones han demostrado que en ocasiones se trata de restos de otra época. El caso más característico es el de la cueva de Cofresnedo (Cantabria) donde un depósito de armas de la Edad del Hierro apareció junto a los restos inhumados de un hombre que resultaron pertenecer al Bronce Antiguo una vez analizados (RUIZ Y SMITH, 2001; 2003: 163; HIERRO, 2002: 113). Podemos entender esta elección como un método de refuerzo del carácter ritual del don o como una asociación ritual intencionada por motivos que se desconocen, puesto que el individuo de la Edad del Bronce era visible en la Edad del Hierro. Esta opción ya ha sido propuesta en varios casos. Por un lado en la cueva de Roche Albéric (Couvin, Francia), donde restos de fauna, cerámicas y metales del periodo La Tène fueron encontrados en asociación con tres cráneos pertenecientes al Bronce Final (WARMENBOL, 2007: 540). Por otro lado existen fenómenos parecidos para etapas posteriores, como el de la cueva de Barandas (Cantabria) y la de Arlanpe (Vizcaya). En el primer caso, las dataciones de una cerámica tipo "La Brazada" y un resto de bóvido apuntan a que el depósito se realizó en la Edad del Hierro (s. VII a.C. y s. I a.C. respectivamente), mientras que el análisis del calcáneo humano data del s. I d.C (RUIZ Y SMITH, e.p.). En el segundo caso, se realizaron dos "fosas de ofrendas" muy próximas a dos inhumaciones de la Prehistoria reciente, depósito que se interpreta como parte de un ritual de defixion en el que se necesitaba la presencia de muertos (GUTIERREZ et alii, 2012: 245-246).

La posibilidad de que la presencia de restos humanos en cuevas suponga la evidencia de sacrificios humanos no puede ser descartada puesto que las fuentes escritas informan acerca de su práctica entre los pueblos del occidente y norte de la Península Ibérica para sellar pactos (Livio Per.49), practicar la adivinación (Estrabón, Geogr. 3, 3, 6) o como sacrificio a los dioses por parte de los montañeses (Estrabón, Geogr. 3, 3, 7; Plutarco, quaest. Rom.83). Además, sacrificios de este tipo han sido localizados en otras cuevas de la Europa occidental del mismo periodo como en la cueva del Trou de l'Ambre (Éprave, Bélgica), Trou de la Coupe (Charente, Francia) o la cueva de Býčiskála (Bohemia, República Checa) (MARIËN, 1970; 
GREEN, 1997: 84,86; DUCONGÉ y GÓMEZ DE SOTO, 2007: 480; WARMENBOL, 2007: 540-541). De todas las cuevas estudiadas, cabe la posibilidad de propuesta de este tipo en tres casos: la cueva de Ojo Guareña (Burgos), La cueva del Puente (Burgos) y la cueva de La Graciosa II posiblemente relacionada con La Graciosa I (Cantabria).

En el primer caso, los restos del individuo indican que puede tratarse de la evidencia de un sacrificio humano ofrecido a la/s dinividad/es subterránea/s de la cueva, pues este individuo joven podría no haberse introducido en la cueva por propia voluntad como mantienen los investigadores (RUIZ VELEZ, 2009) sino haber sido conducido por los oferentes. Por otro lado, el caso de la Cueva del Puente es interesante puesto que, según las inscripciones, en ella "entran diez personas y salen nueve" (ORTEGA, 1999:258-263). En la Graciosa I aparecen los restos de varios individuos a los que les falta la cabeza, localizando en La Graciosa II ocho cráneos sin cuerpo (RASINES, 1986-1988; VALLE Y SERNA, 2003: 386-387), por lo que se plantea que el ritual de ambas estuviera relacionado con las "cabezas cortadas". Algo que también se podría plantear para el cráneo aislado hallado en Riocueva (Cantabria) (MORLOTE et alii, 1996: 239; FERNÁNDEZ, 2002). Por último, las 2 cabezas de fémur perforadas de la cueva de Lamadrid (Cantabria) (MORLOTE et alii, 1996: 244; RUIZ Y MUÑOZ, 2013: 233), que debido a su morfología no parecen fusayolas, podrían tener un origen humano y una función de colgante como talismán. Esta hipótesis se ha propuesto en piezas similares, de tal manera que su función protectora quedaría reforzada en el caso de que se tratase de los restos de un sacrificio conservados a modo de reliquia o talismán (ALFAYÉ, 2009: 310-311). Por último se plantea su presencia también como muestra de la realización de rituales de paso no superados. Sería el caso de Ojo Guareña, un joven que se habría adentrado en la cueva para superarlo pero que al perderse murió en el interior, y de la cueva del Puente, de la que entran diez y solo nueve llegan al final, puesto que uno ha regresado sin haber superado el ritual.

Hay que indicar que parece existir una preferencia por la conservación de los huesos del cráneo. A pesar de ser frágiles, destacan los hallazgos de esta zona del cuerpo en los yacimientos en cueva, algo que puede estar relacionado con la importante simbología que para los pueblos del ámbito cultural indoeuropeo tenía la cabeza.

\section{CUEVAS CON RESTOS DE FAUNA. EL SACRI- FICIO Y EL BANQUETE COMO FORMA RITUAL}

Seguramente, los restos de fauna vinculados con los restos de la Edad del Hierro fueron depositados allí de manera intencional formando parte del ritual que se desarrolló en su interior. La variedad mejor representada son los ovicápridos (oveja/cabra), algo que concuerda con la información que Estrabón (Geogr. 3, 3, 7) aporta de los montañeses, de los que explica que "se alimentan sobretodo de carne de cabra y sacrifican a Ares un macho cabrío". Como se indica en este pasaje, puede que estos sacrifi- cios se relacionaran con el Ares indígena, identificado en la zona como Taranis, Cosus o Erudino (PERALTA, 2003: 221231; TORRES, 2010: 708). Otras especies bien representadas son las pertenecientes al género bos y los suidos. En cuanto a los primeros, destaca la aparición de 9 de sus huesos nasales en las cuevas cántabras de Los Moros (un nasal), el Aspio (dos) y la Llusa (seis), que anteriormente habían sido clasificados como "útiles ahorquillados realizados en costilla" (SERNA et alii, 1994: 375; MORLOTE et alii, 1996: 241, 266, 274; GÓMEZ, 2003: 223). Su presencia parece indicar que esta parte de la cabeza del animal poseía una importancia simbólica relevante por la cual se conservó y depositó en la cueva, del mismo modo que ocurre con los fragmentos de cráneos humanos.

Ningún animal ha aparecido completo, lo que parece indicar que, si su carne fue consumida en el trascurso del ritual que se llevaba a cabo en la cueva, tuvo que ser en el exterior. Todo apunta a que, después de la celebración, se extraía una muestra de lo consumido y se depositaba en el interior de la gruta, un ritual muy similar al funerario que se detecta en la Celtiberia (PERALTA, 2003: 242, 247). Una excepción la encontramos en el Puyo. Al ser un abrigo y estar casi al aire libre, lo más seguro es que la cremación se realizase en la hoguera cuyos restos han sido descubiertos bajo el túmulo excavado, y que el consumo del banquete funerario también tuviera lugar allí mismo. Algo que refuerza esta hipótesis es la presencia en este lugar de un banco corrido construido alrededor de la gran piedra central de este yacimiento, pues Estrabón (Geogr. 3, $3,7)$ cuenta cómo los montañeses celebraban banquetes sentados en él (Fig. 4).

\section{RITUALES CON FUEGO}

En estas cuevas se han localizado hogueras, carbones y materiales con trazas de su uso.

En cuanto a las posibles hogueras, ya indica R. Sanz que "ningún significado práctico tiene encender lumbres en zonas interiores de cuevas" (SANZ, 1992: 27). Su razón debe ser mágico religiosa, seguramente relacionada con algún intento de purificación. Los carbones aparecen dispersos por la sala donde se encuentran los materiales, como la Sala de los Pendants de Cofresnedo, cuyos $60 \mathrm{~m}^{2}$ poseen un nivel completo de suelo ceniciento (RUIZ Y SMITH, 2003: 166). También aparecen en el interior de hoyos o cubetas (Tío Marcelino, Coventosa, Barandas), encima de repisas (Coventosa) o de estalagmitas (SMITH Y MUÑOZ, 1984: 131; RUIZ Y MUÑOZ, 2013: 211-212; SMITH et alii, e.p.) (Fig. 5). Todo lleva a pensar que durante el ritual se realizaría un fuego en algún lugar externo a la cavidad cuyos restos se recogerían y se esparcirían/colocarían en la sala correspondiente del interior en la que continuaría la ceremonia. Algunas de las cerámicas depositadas en el interior de las cavidades, como en el caso del Aspio (Cantabria), parecen haber tenido la función de transportar estos carbones ya que se han hallado con las cenizas en su interior (SERNA et alii, 1994: 376). Hay que señalar que la 


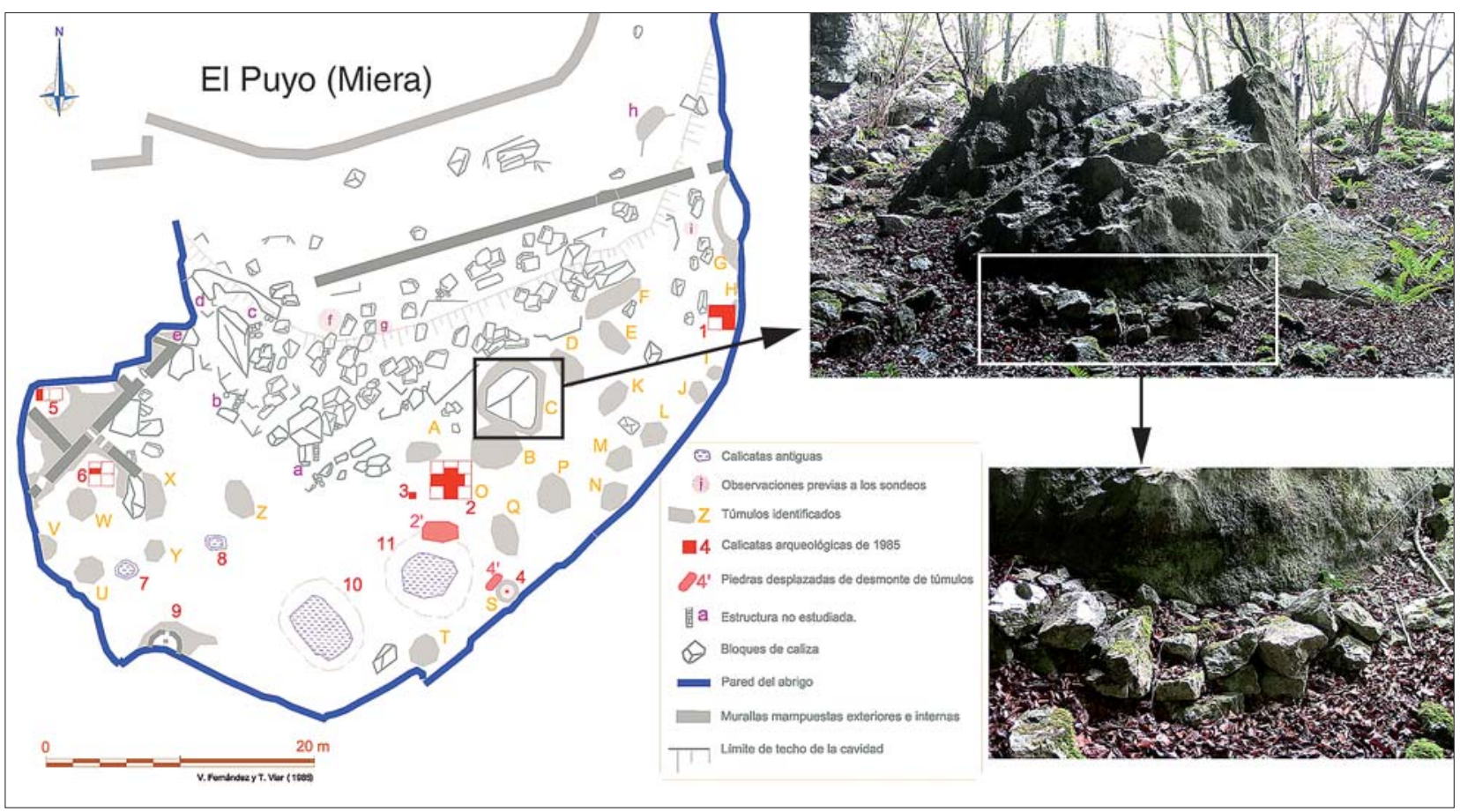

Fig. 4. Situación de la gran piedra central del abrigo del Puyo (La Cárcoba, Miera, Cantabria) y posible banco adosado a ella que pudo tener su origen en la Edad del Hierro (fotografía realizada por la autora, C.A.E.A.P.). / Location of the big central rock at the Puyo rock shelter (La Cárcoba, Miera, Cantabria) and what could be a bench alongside it, which origin could go back to Iron Age (photograph taken by the author, C.A.E.A.P.).

realización de hogueras y el esparcimiento de cenizas y carbones parece ser una constante en este tipo de yacimientos desde el Bronce Final (Solacueva de Lakozmonte en Jócano, Álava, o Armontaitze en Guipúzcoa) hasta la tardoantigüedad e inicios de la Edad Media (Calero II, La Garma, Las Penas, Riocueva...en Cantabria) (LLANOS, 1991; ARMENDARIZ et alii, 1989).

La acción del fuego es perceptible en muchos materiales ya sean estos óseos (cabezas de fémures perforadas de Lamadrid, restos de fauna del Puyo, restos humanos de Cofiar o Los Trillos), cerámicos (Cudón, Aspio), líticos (Puyo), en madera (objeto en forma de lanza y peines del Aspio) (Fig.1) o restos vegetales (como los granos calcinados de Cofresnedo) (Fig. 7) (BOHIGAS et alii, 1992: 233; SERNA et alii, 1994: 374,377,380-383; MORLOTE et alii, 1996: 227,244,274,276; RUIZ Y MUÑOZ,
2009: 179; SMITH et alii, e.p.). La acción del fuego en estos materiales parece ser intencionada, quizás porque formaba parte del ritual previo a la deposición de los objetos en la cueva, a excepción del Puyo, donde parecen haber sido dejados in situ donde se realizó la hoguera. Puede que formara parte de una condición para su deposición en la cavidad, que se realizara a modo de "inutilización ritual", o como método de "purificación" de objetos ya utilizados que iban a ser consagrados (Fig. 1.4).

\section{OTRAS EVIDENCIAS MATERIALES DEL RITUAL}

Uno de los criterios fundamentales para determinar que la cueva se utilizó como lugar ritual es el hallazgo en su interior de elementos que lo demuestren (VIDAL et alii, 2000: 65). Algunos de ellos han sido catalogados de "de-
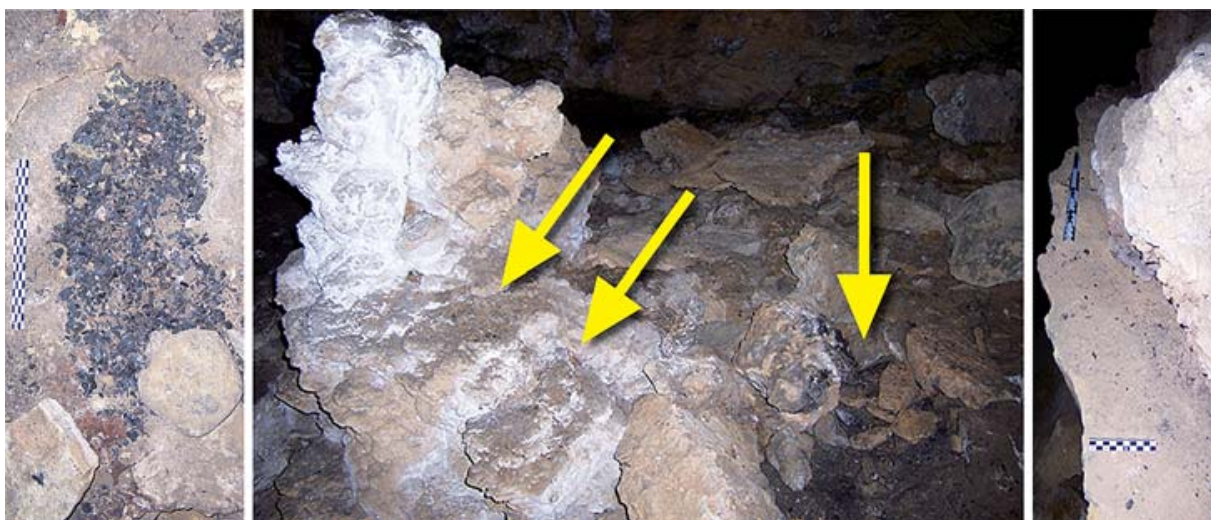

Fig. 5. Ejemplo de dispersión de carbones en la cueva de la Coventosa (Val de Asón, Arredondo, Cantabria). A la izquierda de manera concentrada en un gour que ha sido excavado para modificarlo. En el centro aparecen los carbones dispersos tanto sobre la estalagmita como en la base de ésta. A la derecha aparecen carbones dispersos en una estrecha repisa de la pared de la sala (Fotografías realizadas por la autora, C.A.E.A.P). I Example of dispersion of charcoal at Coventosa Cave (Val de Asón, Arredondo, Cantabria). On the left, inside a modified rimstone dam. On the centre, charcoal dispersed both over the stalagmite and its base. On the right, dispersed charcoal on a small shelf on the room wall (photograph taken by the author, C.A.E.A.P.). 
pósitos" u "ofrendas" en publicaciones anteriores debido tanto a su naturaleza como a su contexto arqueológico. En otros casos, su presencia es difícil de aclarar, aunque su sentido funcional ha sido descartado. Por otro lado hay que pensar que algunos de estos materiales pueden corresponder a restos de una celebración religiosa acontecida en su interior. En ese caso, podemos pensar que existió una determinación por la cual se dejó una muestra de este acontecimiento en el mismo lugar en el que se desarrolló.

Algunos de estos restos no dejan duda acerca de su sentido ritual, mientras que en otros casos esta asignación necesita un estudio en profundidad. Se han categorizados todos ellos, haciendo hincapié en los que otorgan información a nivel simbólico así como citando otros que pueden servir de referencia en investigaciones posteriores. Además se proponen hipótesis en el caso de que se tratara de elementos rituales.

\subsection{Recipientes: cerámica y madera}

Los recipientes, ya sean cerámicos o de madera, son las evidencias arqueológicas más abundantes halladas en estas cuevas. Sabemos por Estrabón (3, 3, 7) que los montañeses utilizaban "vasos de madera", costumbre que compartían con otros pueblos célticos como los galos. Se han conservado en pocas ocasiones, como en la cueva de Hoyo de los Herreros (Reocín, Cantabria) donde se hallaron los fragmentos pertenecientes a cinco recipientes de madera realizados con torno (MORLOTE et alii, 1996: 224-225; TORRES, 2005: 101; GOMEZ, 2003: 223).

En cuanto a la cerámica, las formas más comunes son las de perfil en "s", las de tipo "La Brazada", las de tipo orza, las denominadas "celtibéricas" y la común romana (BOHIGAS et alii, 1984: 140-142; MORLOTE et alii, 1996: 204-210,219; RUIZ, 1996: 127-130; PERALTA, 2003: 70; RUIZ Y SMITH, 2003: 176). Estas tipologías son las mismas que se localizan en yacimientos al aire libre. No obstante, el análisis petrográfico de algunas de ellas (Cofresnedo y el Aspio) demuestra que han sido elaboradas con desgrasantes procedentes de estalagmitas de cueva, lo que indica que probablemente se realizarían ex proceso para su deposición en las cavidades (OLAETXEA, 2000: 53). El resto, a pesar de poseer la forma de las cerámicas utilizadas cotidianamente, se habrían seleccionado para ser depositadas como don (RUIZ, 1996: 143). No obstante hay excepciones como las cerámicas de la cueva de la Zurra (Asturias), decoradas con elementos plásticos e incisos similares a los hallados en otros contextos rituales de la Beturia Céltica y del ámbito galaico (BERROCAL, 1994, 2004; MAYA, 1996). Además, aparecieron completas, algo que ocurre también en otras cuevas como en La Brazada, Lamadrid y La Tobalina (RUIZ Y MUÑOZ, 2013: 233). Esto es importante puesto que la mayoría de la cerámica localizada aparece fragmentada, como si esta acción formara parte del ritual (Fig. 1.3). Por último hemos de pensar en si la ofrenda fue realmente el recipiente o si éstos eran los contenedores de la verdadera ofrenda de naturaleza perecedera como podría ser el caso de perfumes o alimentos.

\subsection{Objetos personales y/o de adorno}

Por otro lado se han localizado adornos entre los que se encuentran placas, cuentas, fíbulas, colgantes, remaches y anillos. Podemos pensar que estos objetos personales bien pudieron ser ofrendas personales a la divinidad o haber formado parte del ajuar del difunto (como se interpreta en el caso de las cuevas vascas de Antzuzkar, de Santimamiñe, de Los Moros o Peña Rasgada, de Lazaldai y de la Cueva del Hueso) (LLANOS Y AGORRETA, 1962; MARCOS, 1982: 40; CAPRILE, 1986:162-164; MAYA, 1983:246; 1988:105; ALTUNA et alii, 1995; GARCÍA QUIRÓS, 1995: 207). Estas hipótesis se proponen debido al hallazgo de paralelos tipológicos de estas piezas tanto en yacimientos de hábitat como en necrópolis. De entre estos objetos destaca la cuenta oculada de pasta vítrea hallada en la cueva de Cofresnedo, puesto que, además de ser un elemento profiláctico, es un pieza que aparece con frecuencia en otras cuevas europeas de esta misma cronología. Es el caso de la "grotte-sanctuaire" de l'Ortiguet (Sainte-Eulalie-deCernon, Aveyron, Francia), la cueva de Creux Beurnichot (Chenôves, en Saône-et-Loire, Bourgogne, Francia) o la cueva-abrigo de La Baume Du Four (Boudry, Bourgogne, Francia) entre otras, cuyos usos rituales van desde su utilización como santuario hasta su función sepulcral (FITCHER, 1982; PUJOL et alii, 1998: 129; JEUNOT, 2007: 494; KAENEL Y CARRARD, 2007: 499-532).

\subsection{Armas: cultura guerrera}

M. Almagro mantiene que "la guerra, aunque no fuera continua, afectaría a todo el sistema cultural, desde la economía hasta la religión" (ALMAGRO, 2002:64). Por este motivo se entiende que tuvieron que desarrollarse numerosas ceremonias y rituales relacionados con la cultura guerrera, cuyas evidencias más claras son las armas como ofrenda ritual. Así, entre las armas descubiertas en estos contextos encontramos cuchillos o puñales en el Aspio, Cofresnedo, Cigudal, Covarona, Falso Escalón y Calero II en Cantabria (SMITH Y MUÑOZ, 1984, 2010: 682; SMITH, 1985: 51,65; BOHIGAS, 1986-87: 122; MORLOTE et alii, 1996: 231, 249, 271; RUIZ Y SMITH, 2003: 87; RUIZ, 2009: 181). También algunas puntas de flecha/lanza/dardo como en Portillo del Arenal (aunque hay quien opina que podían ser ganchos de huso tardoantiguos), La Cuquisera, Las Cabras o La Bona, Ziguste y Cofresnedo en Cantabria (SMITH, 1985: 57; BERMEJO et alii, 1987: 166; MORLOTE et alii, 1996: 230; MOLINERO, 2000: 199-202; RUIZ Y SMITH, 2003: 88; VALLE et alii, 2005: 265). Incluso regatones como en Cofresnedo (RUIZ Y SMITH 2003: 87), umbos de escudo en esta cueva y las noticias del s. XIX del hallazgo de "escudos de hierro" en la Cueva Mora, Cantabria (BERMEJO et alii, 1987: 172; PERALTA, 2003: 70). Así mismo se han localizado elementos de caballería en Cofresnedo y Coventosa (Cantabria) y en Pueblo Bajo de Lledías (Asturias) aunque A. Fanjul intuya una adscripción a época tardorromana o altomedieval para el último caso (MORLOTE et alii, 1996: 249, 253; MAYA, 1989: 82; PERALTA, 2003: 67, 195; 
RUIZ, 2009: 146; FANJUL et alii, 2010: 20; FANJUL, 2011: 97). Destaca de entre ellos el denominado "depósito de guerrero" de Cofresnedo, en el que también se localizó la cuenta de vidrio comentada anteriormente.

Con estos datos se puede intuir la existencia de dos funciones de las armas en las cuevas en el caso en el que éstas hayan sido depositadas con un sentido simbólico: por un lado su papel como ajuar funerario y, por otro, como depósito ritual, quizás realizado en algún tipo de ceremonia de iniciación guerrera para el que eran tan propicias las cuevas (ALMAGRO, 1996; TORRES, 2011:388-389, 391-395). M. Gabaldón propone otros motivos rituales para la localización de armas en lugares de culto, como podría ser la ofrenda (como parte de un botín o como arma personal), el arma sagrada como objeto de culto y el arma como instrumento ceremonial o como tesoro/reliquia (al poder tratarse por ejemplo de armas utilizadas en juegos o competiciones, o que perteneciera a una persona o enemigo relevante socialmente) (GABALDÓN, 2004: 23-29).

\subsection{Herramientas de trabajo: cultura material campesina y artesana}

La importancia de las labores campesina y artesana para la subsistencia y la vida cotidiana, hace necesaria la realización de rituales relacionados con la propiciación de prosperidad. En este sentido, parece que las cuevas estudiadas contienen algunas de estas evidencias.

En algunos casos se trata de hallazgos aislados de herramientas como hachas (Cofresnedo, Covarrubias, Cuatribu, Fresca y Los Santos en Cantabria) (SMITH Y MUÑOZ, 1984; 2010: 688; SMITH, 1985: 51; MORLOTE et alii, 1996: 249, 271; SERNA et alii, 1996; GÓMEZ, 2003: 228; RUIZ, 2009: 153), punzones (Portillo del Arenal, Cudón y Cofresnedo en Cantabria y Santimamiñe y Solacueva de Lakozmonte en el País Vasco) (LLANOS, 1968: 124; MARCOS, 1982: 40; SMITH, 1985: 51; MORLOTE et alii, 1996: 227,230,249; RUIZ Y SMITH, 2003: 87), fusayolas (Las Monedas y el Aspio, Cantabria) o pesas de telar y otros objetos relacionados con el tejido (La Cuquisera, Cofiar, Las Monedas y Aspio en Cantabria, y Santimamiñe en País Vasco) (MARCOS, 1982: 40, MORLOTE et alii, 1996: 213).Es importante señalar que en los siglos VII-VIII d.C., momento en el que aparentemente se reaviva el uso ritual de estas cuevas, este tipo de materiales también son comunes (Cuevas de El Cantal, Los Cirrios, Los Hornucos, La Venta del Cuco... entre otras) (HIERRO, 2002).

Pero en tres casos, todos ellos en cuevas de Cantabria, el número de este tipo de objetos supera los 15. Se trata del depósito de Coventosa (especializado, al estar formado por 17 rejas de arado) (GONZÁLEZ ECHEGARAY, 1971: 139-140; BOHIGAS et alii, 1984: 143; LEÓN, 1993: 22; BARRIL, 2001) y los mixtos de la cueva de Reyes (formado por distintas herramientas de la vida campesina como rejas de arado, un azada, un plantador... etc más un objeto doméstico como es el llar) (Fig. 6) (SMITH, 1996a; PERALTA, 2003: 72-73; SMITH Y MUÑOZ, 2010:
87) y del Aspio (un depósito de objetos para la fabricación del tejido junto con unas pinzas de herrero y un puñal) (SERNA et alii, 1994; MORLOTE et alii, 1996: 273-274; PERALTA, 2003: 72-73). Los dos primeros casos han sido interpretados como ocultaciones en momentos de inestabilidad como podrían ser las Guerras Cántabras (SMITH, 1996a: 189; SMITH Y MUÑOZ, 2010: 689). Esta es una de las opciones, pero hay que contemplar también la posibilidad de que se trate de una ofrenda o depósito ritual $\mathrm{y}$, en este sentido, puede que se realizara de manera colectiva dado el alto número de objetos y la inversión económica que eso supondría para una única persona.

Las herramientas de trabajo pudieron formar parte de las ofrendas depositadas en las cuevas, seguramente en relación a una demanda o agradecimiento relacionado con este tipo de actividades, como se propone para depósitos de este tipo hallados en otras cuevas de Europa occidental (DUCONGÉ Y SOTO, 2007:488).

\subsection{Molinos y alimentos}

La aparición de molinos en las cuevas estudiadas se ha constatado en cinco casos, de los que tres se hallaron en el vestíbulo de entrada (Delante de la Cueva, El Portillo IV y Coventosa, Cantabria) (Fig. 7) (MORLOTE et alii, 1996: 251; GOMEZ, 2003: 222, 228; RUIZ, 2007: 136, 2009: 144) y tres en sala interiores (Maciu, Cofiar o Los Trillos y Cofresnedo Cantabria) (BOHIGAS et alii, 1992: 233 ; MORLOTE et alii, 1996: 25 ; RUIZ Y SMITH, 2003: 182). Todos estos molinos son circulares, razón por la cual los autores señalaban que se trataba de "molinos romanos". No obstante, los molinos circulares son conocidos desde la Segunda Edad del Hierro (TORRES, 2005: 42), por lo que los citados podrían corresponder a esta cronología. En Hoyo de los Herreros (Cantabria) se localizó una mano de moler, que correspondería a un molino barquiforme. Si el molino participó en la ceremonia ritual, pudo hacerlo de distintas formas: como ofrenda en sí misma (pudiendo ser fragmentada ritualmente), como parte activa del ritual que contemplaba la manipulación de alimentos (actividad en la cual se fragmentó y se abandonó allí), o ambas posibilidades a la vez.

También se han encontrado restos de alimentos. La Cueva de los Moros o Peña Sesgada (Atauri, Álava) posee un depósito en el cual se han hallado restos humanos, con distintos objetos y restos de granos de trigo quemados junto con bellotas (LLANOS Y AGORRETA, 1962). Si consideramos que el depósito es sepulcral, hay que pensar que la ofrenda alimenticia formaba parte del ajuar del difunto. Por otro lado, al fondo de la galería principal de la cueva de Cofresnedo (Cantabria) se localizaron los restos de un cesto de mimbre y, detrás de él, una amplia concentración de carbón vegetal cubriendo la superficie de las cubetas naturales de calcita, encontrando en una de ellas una acumulación de granos de cereal carbonizados datados en 2055+-30 B.P (170 a.C.-20 d.C. fecha calibrada) (RUIZ Y MUÑOZ, 2009: 179; SMITH et alii, e.p.) (Fig. 7). En cuevas de época romana (como en Las Brujas, Cantabria) o tardoantiguas y medievales (Riocueva y Las 

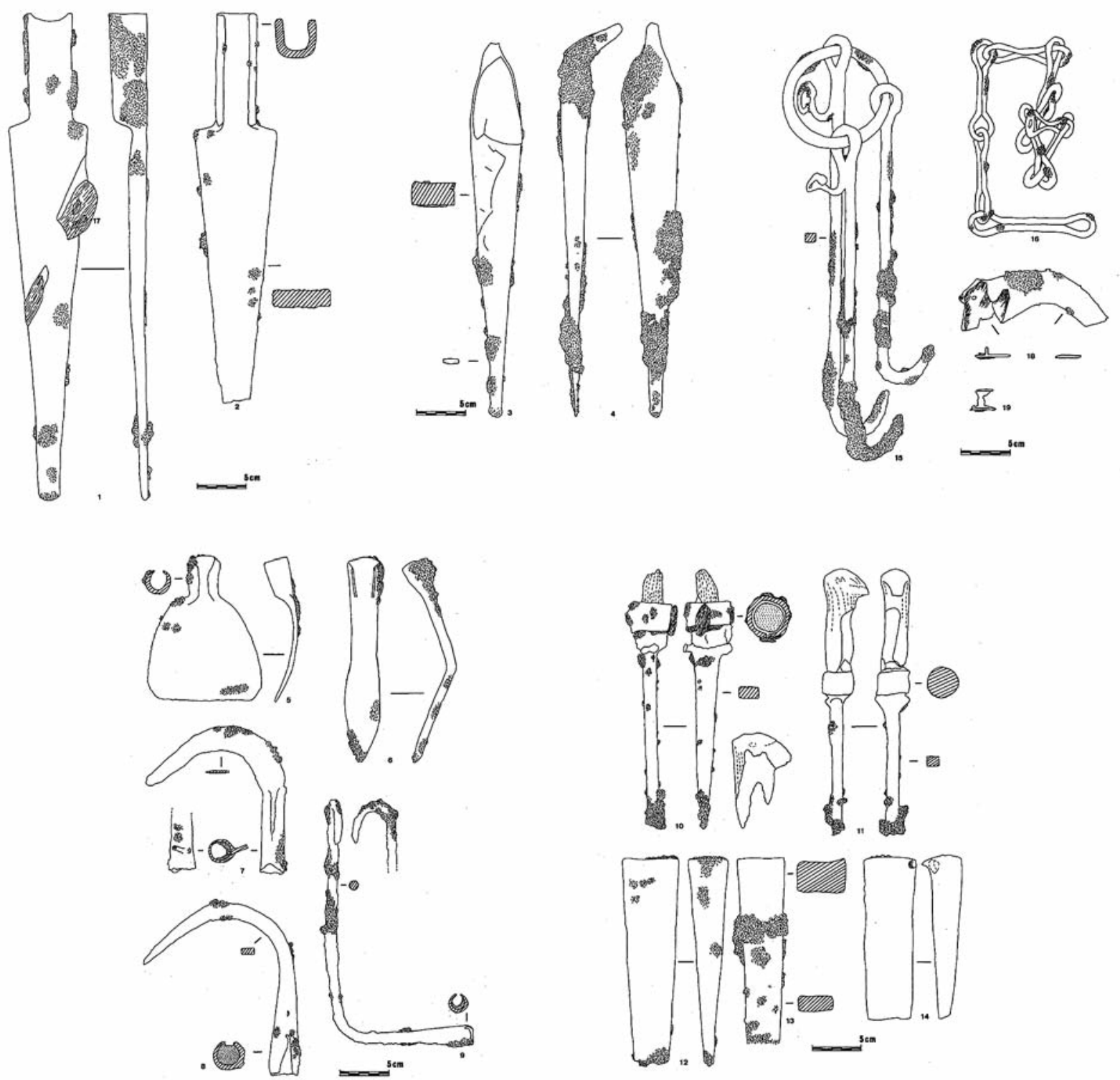

Fig. 6. Depósito de herramientas localizado en la cueva de Reyes (Matienzo, Ruesga, Cantabria) (SMITH, 1996a). / Tools deposit found at Reyes Cave (Matienzo, Ruesga, Cantabria) (SMITH, 1996a).

Penas, Cantabria, con restos de gallina y semillas de trigo o Iruaxpe en Guipúzcoa con restos faunísticos y cereales) son también conocidos estos casos (BOHIGAS et alii, 1984: 143; HIERRO, 2002: 119; VALLE et alii, 2005). Gracias a M. Dumiense (De Corr. Rust) y a los Concilios Visigóticos (de Braga II y III) sabemos que en el siglo VI d.C. las ofrendas alimentarias eran comunes en las prácticas rituales consideradas paganas, informando de una costumbre arraigada en las sociedades del norte peninsular, por lo que su origen se situaría en un momento muy anterior como la Edad del Hierro.

Se ha planteado que los depósitos de cereales o frutos provenientes de la agricultura, se relacionaran con una ofrenda a la divinidad con ocasión de las cosechas
(SMITH et alii, e.p.). Desconocemos su intención, pero ya hemos visto que en el caso de Solacueva puede tener un sentido funerario, lo que plantea la variedad y complejidad en cuanto a la intención de este tipo de ofrendas si de ello se tratara. En otras cuevas del mediterráneo y la Europa occidental se ha evidenciado la presencia de este tipo de sacrificio no cruento como en Baume Rouge (Hérault, Francia) (VIDAL et alii, 2000), las cuevas-santuario ibéricas con vasos caliciformes que evocan la práctica de libaciones o su función como contenedores de alimentos, o el caso del altar del santuario subterráneo de la Encarnación (Caravaca, Murcia) donde se hallaron restos de una libación compuesta de leche humana, ovina y miel (GONZÁLEZ-ALCALDE, 1993: 72; RAMALLO, 1997: 265). 


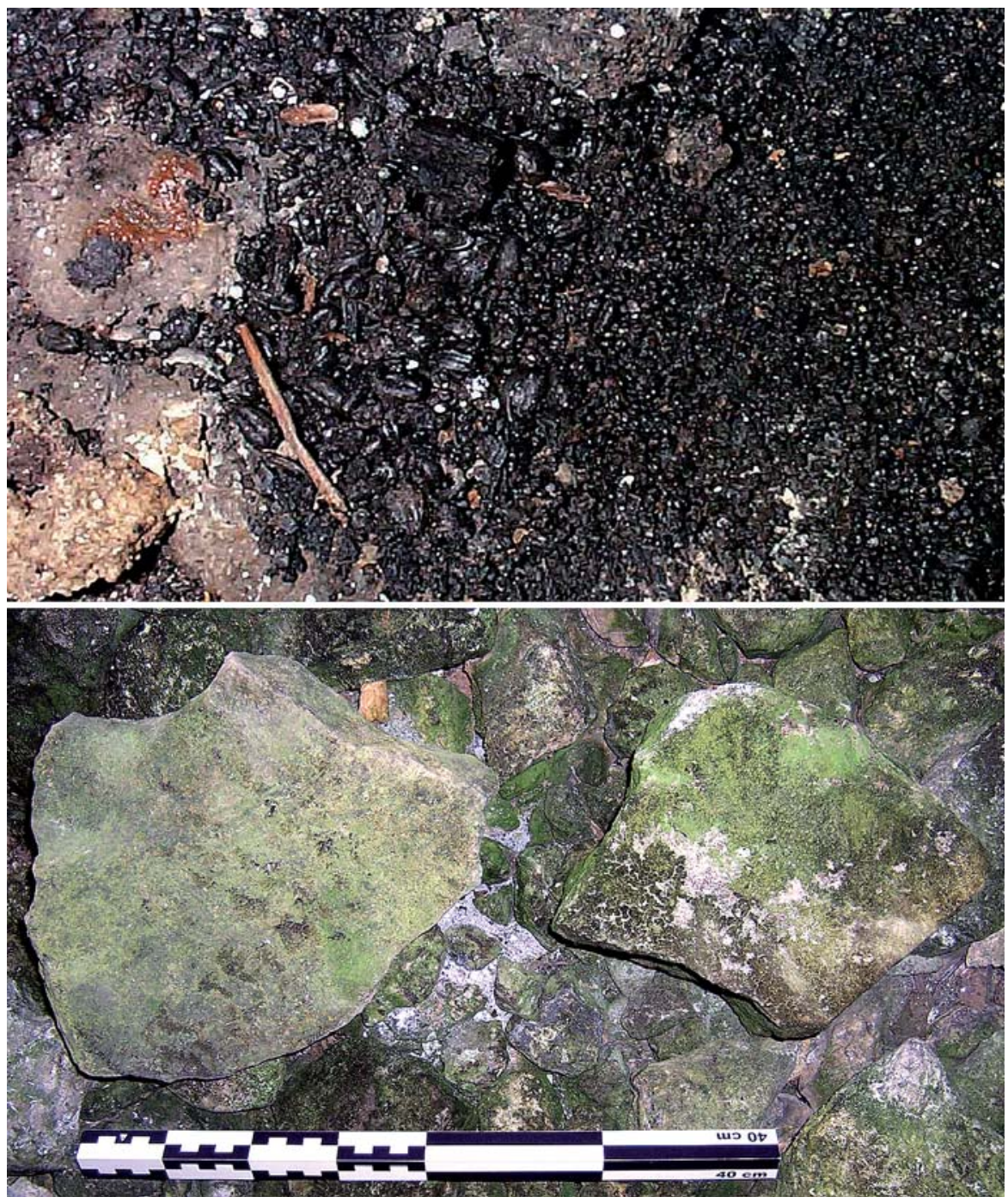

Fig. 7. Arriba, granos de cereal carbonizados localizados en el interior de la cueva de Cofresnedo (Matienzo, Ruesga, Cantabria) (fotografía cedida por el proyecto "La Prehistoria Reciente de Matienzo"). Abajo, fragmentos de molinos circulares localizados en el vestíbulo de la cueva de La Coventosa (Val de Asón, Arredondo, Cantabria) (fotografía realizada por la autora, C.A.E.A.P.). / On the top, carbonized cereal grains located inside Cofresnedo Cave. (Matienzo, Ruesga, Cantabria) (image courtesy of the "La Prehistoria Reciente de Matienzo" Project). On the bottom, fragments of circular mills located at the corridor of Coventosa Cave (Val de Asón, Arredondo, Cantabria) (photograph taken by the author, C.A.E.A.P.).

\subsection{Monedas}

En algunos de los yacimientos estudiados han aparecido monedas acuñadas en cecas indígenas o que datan de la última centuria antes de Cristo. En el País Vasco se recuperaron en 19708 denarios ibéricos en plata en la cueva de Usategi (Ataun): 4 de la ceca de Bascunes-Beganda, 2 de la de Segóbriga y 2 de la de Turiaso, acuñadas entre el 102 y el 82 a.C. (ESTEBAN, 1990: 154,375-377; PEÑALVER 2005: 241). No se especifica en qué lugar aparecieron, pero pudo ser en la zona más alejada de la entrada, donde J. M. Barandiarán (1977: 201) indicó que aparecieron "fragmentos de alguna urna cineraria depositada, al parecer, de la Edad del Hierro", de las que no contamos con evidencia alguna en la actualidad. En la cueva de Amalda (Zestoa) se localizaron dos monedas de bronce de la ceca Bascunes y en la cueva de Lokatza
(Ataun) un as de bronce de la de Turiaso (ALTUNA et alii, 1984: 123,131-132; ESTEBAN, 1990: 154,315,377; AGIRRE et alii, 2005: 159 y 2006: 61; PEÑALVER, 2005: 241). En Cantabria se conoce únicamente el caso del Covarón, donde apareció un bronce de Segóbriga. La "moneda" citada por J. Gómez Arozamena (2003: 225) en la cueva de Barandas no puede ser adscrita con seguridad a la Edad del Hierro dado su nefasto estado de conservación, la ausencia de motivos decorativos y escritura en sus dos caras. Además posee un peso y cospel menor a las monedas de esta época conocidas en Cantabria1.

Este tipo de ofrenda resulta común en las cuevas-santuario mediterráneas tanto de la Península Ibérica como de la zona meridional francesa. No obstante, en estas últimas se han hallado en grandes cantidades, como en Rajal del Gorp (Aveyron) con 411 monedas o en la cueva de l'Ourtiguet

${ }^{1}$ La moneda ha sido consultada gracias a la información y fotografías cedidas por el MUPAC. Agradezco la ayuda prestada para su análisis a Antxoka Martínez. 
(Sainte-Eulalie-de-Cernon, Aveyron) con 160 (PUJOL et alii, 1998; VIDAL et alii, 2000: 65-69). En las cuevas del área estudiada su número es más modesto, un fenómeno que resulta similar al de algunas cuevas de la Borgoña francesa (como en La Balme-D'Épy, Château de la Roche o La Baume du Four) y del Suroeste galo (Rouffignac) (ARCELIN Y BRUNAUX, 2003:112; DUCONGÉ Y GÓMEZ DE SOTO, 2007:479; JEUNOT, 2007; KAENEL Y CARRARD, 2007:506).

A excepción de los casos de la cueva de Amalda y del Covarón, los hallazgos monetarios aparecieron aislados y ninguno en relación a restos humanos, lo que hace complicada su interpretación ritual. No obstante, si fuera esa su naturaleza, habría que entenderlos como objetos con sentido simbólico en un momento en el que la moneda se convierte en un objeto de valor.

\section{CONCLUSIONES}

Es importante que se reflexione acerca del fenómeno ritual acontecido en las cuevas en este área, pues sus grutas son el lugar sagrado prerromano que más información aporta para comprender el ámbito religioso de sus sociedades. Por este motivo, es necesaria la realización de un estudio pormenorizado de sus yacimientos y de sus materiales arqueológicos. Gracias a la revisión de la información publicada y a su análisis, se ha podido comprobar que estos lugares pueden estar mostrando una gran diversidad de rituales que no pueden quedar limitados a su interpretación como funerarios, como se había propuesto hasta ahora. En éstos cabe la posibilidad de la práctica de rituales de paso, sacrificios cruentos (humanos y animales) y no cruentos, así como de la celebración de banquetes y el depósito de recipientes, objetos personales y de adorno, armas, herramientas, alimentos y monedas. En todos estos rituales el fuego tuvo un importante papel, ya fuese a modo de hoguera, de dispersión de carbones o como método de transformación de las ofrendas. El presente trabajo puede servir de ayuda en el estudio de este fenómeno tanto a escala regional como en relación al occidente europeo, a la espera de estudios específicos.

\section{AGRADECIMIENTOS}

No podía finalizar este trabajo sin dar las gracias a todos aquellos que, de una u otra manera han ayudado a la elaboración de este trabajo. Gracias a Kechu Torres, Luis Berrocal, Virgilio Fernández, Alis Serna, Peter Smith, Emilio Muñoz, Antxoka Martínez, Elena Aznar, Elina Rodríguez, David Vacas y Juan Carlos. A Tere, Julio, Valle y Miguel. También al proyecto Monte Bernorio en su entorno y al IMBEAC, así como a cada uno de sus integrantes.

\section{BIBLIOGRAFÍA}

AGIRRE, J; MORAZA, A.; MUJIKA, J.A.; REPARAZ, X. Y TELLERIA, E

2005 Sierra de Aralar (Unión Enirio Aralar). Arkeoikuska 2004, 153-159.
AGIRRE, J; ÁLVAREZ, D.; LAMIKIZ, X.; MORAZA, A. Y MUJIKA, J.A.,

2006 Kulturbideak Aralarren, col. Natura Gipuzko. Bilduma 1, Diputación Foral de Guipúzcoa, San Sebastián.

ALFAYÉ, S.

2009 Santuarios y rituales en la Hispania Céltica. BAR International Series 1963, Oxford.

2011 Imagen y ritual en la céltica peninsular. Toxosoutos, Galicia.

ALFAYÉ, S. Y RODRÍGUEZ-CORRAL, J.

2009 Espacios Liminales y prácticas rituales en el Noroeste peninsular. Paleohispánica 9, 107-111.

\section{ALMAGRO-GORBEA, M}

1996 Lobos y ritos de iniciación en Iberia. Iconografía ibérica e iconografía itálica. Presupuestos de interpretación y lectura, Coloquio Internacional, 11-13 noviembre 1993, Roma, 103-127.

2002 Urbanismo y sociedad en la Hispania Húmeda. Los poblados fortificados del noroeste de la Península Ibérica: formación y desarrollo de la cultura castreña, Navia, 47-79.

ALTUNA, J.; BALDEÓN, A. y MARIEZKURRENA, K.

1984 La cueva de Amalda (Zestoa, País Vasco). Ocupaciones Paleolíticas y Postpaleolíticas. Fundación José María de Barandiarán, San Sebastián.

ALTUNA, J.; ARMENDARIZ, A.; ETXEBERRÍA, F.; MARIEZKURRENA, K.; PEÑALVER, J. y ZUMALABE, F. J.

1995 Carta Arqueológica de Guipúzcoa, Vol II: Cuevas. Munibe, suplemento 10, San Sebastián.

ARCELIN, P. et BRUNAUX, J. L.

2003 Cultes et sanctuaires à l'Âge du Fer. Gallia, 60, 1-268.

ARDÈVOL, E. y MUNILLA, G.

2003 Antropología de la Religión. Una aproximación interdisciplinar a las religiones antiguas y contemporáneas. UOC, Barcelona.

ARIAS, P. y ARMENDARIZ, A.

1998 Aproximación a la Edad del Bronce en la región cantábrica. A idade do Bronce en Galicia: novasperspectivas, Cuadernos do seminario de Saragadellos, 77, 47-80.

ARMENDARIZ, A; PALET, A. y VILLATE, E.

1989 Análisis del contenido de una vasija cerámica prehistórica de la Cueca de Armontaitze (Ataun, Guipúzcoa). Munibe 41, 87-91.

BARANDIARÁN, J. M.

1977 Excavaciones en Jentilbaratza y Kobalde (Ataun) (Campaña de 1971). Munibe 3-4, 195-212.

BARRIL, M.

2001 Pre-roman Ard-shares in Cantabria, In the Archaeology of the Matienzo Depression, North Spain. BAR International Series 975, 177-197. 
BARROSO, R.; BUENO, P.; CAMINO, J. y DE BALBÍN, R.

2007 Fuentenegroso (Asturias), un enterramiento del Bronce Final-Hierro en el marco de las comunidades atlánticas peninsulares. Pyrenae 38, vol 2, 7-32.

BERMEJO, A.; FERNÁNDEZ, V.; GÓMEZ, J.; MUÑOZ, E. y SAN MIGUEL, C.

1987 Carta Arqueológica de Cantabria. C.A.E.A.P., Santander.

\section{BERROCAL-RANGEL, L.}

1994 El altar prerromano de Capote. Ensayo sobre el ritual céltico del Suroeste Peninsular, Universidad Autónoma de Madrid, Madrid.

2004 Banquetes y rituales colectivos en el Suroeste Peninsular CUPAUAM 30, 105-119.

\section{BOHIGAS, R.}

1986-87 La Edad del Hierro en Cantabria. El estado de la cuestión. Zephyrus, 39-40, 119-138.

BOHIGAS, R., MUÑOZ, E. y PEÑIL, J.

1984 Las ocupaciones recientes en cuevas. Boletín Cántabro de Espeleología 4, 140-159.

\section{BOHIGAS, R.; MOLINERO, J. T. y MUÑOZ, E.}

1992 Los materiales de cueva Cofiar o de Los Trillos (Hoyo Masayo, Sierra del Hornijo, Soba). Actas del V Congreso Español de Espeleología, Camargo-Santander (1-4 Noviembre de 1990), 229-241.

\section{CABRERA, A.}

2010 El ritual del sacrificio de animales en la cultura ibérica: una perspectiva arqueológica. Tesis doctoral bajo la dirección de Teresa Chapa Brunet, UCM. (http://eprints. ucm.es/11714/1/T32477.pdf)

\section{CAPRILE, P.}

1986 Estudio de los objetos de adorno del Bronce Final y de la Edad del Hierro en la provincia de Álava. Estudios de Arqueología Alavesa, 14 (monográfico), Vitoria-Gasteiz.

\section{DUCONGÉ, E. y GÓMEZ DE SOTO, J.}

2007 Les dépôts à caractère cultuel en milieux humides et dans les cavités naturelles du Centre-Ouest de la France à l'Âge du Fer, L'Âge du Fer dans l'arc jurassien et ses marges. Dépôts, lieux sacrés et territorialité à l'âge du Fer. Actes du XXIXe colloque international de l'AFEAF, Bienne, 5-8 mai, 2005, vol 2, 477-492.

\section{ESTEBAN, M.}

1990 El País Vasco en época romana. Cuadernos Universitarios, San Sebastián.

FANJUL, A.

2011 Las últimas cuevas. Observaciones entorno a la ocupación histórica de las cuevas astur-leonesas. Arqueología y territorio medieval 18, 91-116.

FANJUL, A.; ÁLVAREZ PEÑA, A.; HIERRO, J.M. y SERNA, A.

2010 El santiariu astur-romanu en cueva, d'el Ferrán (Piloña). Asturies 19, 14-23.
FERNÁNDEZ ACEBO, V.

1984 Afloramientos cársticos en Cantabria. Boletín Cántabro de Espeleología 5, 11-14

2002 Paleontología humana en Cantabria. Sautuola 8, 57-96.

2010 La Cueva de El Puyo (Miera). Necrópolis de incineración en la vertiente marítima de Cantabria. A. Serna, A. Martínez y V. Fernández (coords.): Castros y Castra en Cantabria: fortificaciones desde los orígenes de la Edad del Hierro a las guerras contra Roma. Catálogo, revisión y puesta al día. ed. Acanto, Santander, 551-562.

\section{FISCHER, B.}

1982 Le tresôr de Chenôves. Revue Archéologique de l'Est et du Centre-Est, 127, 99-109.

\section{GABALDÓN, M. M}

2004 Ritos de armas en la Edad del Hierro. Armamento y lugares de culto en el antiguo Mediterráneo y el mundo celta. Anejos de Gladius 7, Madrid.

GARCÍA, D.

1993 Entre ibères et ligures. Lodévois et moyenne Vallée de l'Hérault protohistoriques. Revue Archéologique de Narbonnaise, Suplément 26, Paris.

\section{GARCÍA DÍEZ, M. y GONZÁLEZ MORALES, M. R.}

2003 En torno al llamado "arte esquemático-abstracto": a propósito de unas fechas de Covalanas (Ramales de la Victoria, Cantabria). Veleia 20, 227- 241.

\section{GARCÍA QUIRÓS, M. P.}

1995 Reseña de las Cartas Arqueológicas de los Concejos de Avilés y Castrillón. Excavaciones arqueológicas en Asturias 1991-1994, 205-210.

\section{GÓMEZ AROZAMENA, J.}

2003 Arte esquemático-abstracto. Una actualización. C.A.E.A.P. Veinticinco años de investigaciones sobre el Patrimonio Cultural de Cantabria, Santander, 215-232.

\section{GONZÁLEZ-ALCALDE, J.}

1993 Las cuevas-santuario ibéricas en el País Valenciano: un ensayo de interpretación. Verdolay 5, 67-78.

2006 Totemismo del lobo, rituales de iniciación y cuevas-santuario mediterráneas e ibéricas. Quaderns de Prehistòria y Arqueologia de Castelló 25, 249-269.

2009 Una aproximación cultural a los vasos caliciformes ibéricos en cuevas-santuarios y en yacimientos de superficie. Quaderns de Prehistòria y Arqueologia de Castelló 27, 83-107.

\section{GONZÁLEZ-ALCALDE, J. y CHAPA, T.}

1993 Meterse en la boca del lobo: una aproximación a la figura del carnassier en la religión ibérica. Complutum 4, 169-174.

\section{GONZÁLEZ ECHEGARAY, J.}

1971 Yugos y arados en la provincia de Santander. Publicaciones del Instituto de Etnografía y Folklore Hoyos Sain 3, 123-168.

GRAU, I.

2000 Territorio y lugares de culto en el área central de la Contestania ibérica. Quaderns de Prehistòria i Arqueologia de Castelló 21, 195-226. 
GREEN, M. J.

2010 El mundo de los druidas. Akal, España.

GUTIERREZ, E.; HIERRO, J. Á.; RÍOS, J.; GÁRATE, D.; GÓMEZ OLIVENCIA, A. y ARCEDERILLO, D.

2012 El uso de la cueva de Arlanpe (Bizcaia) en época tardorromana. Archivo Español de Arqueología 85, 229-251.

HIERRO, J. A.

2002 Arqueología de la tardoantigüedad en Cantabria. Yacimientos en cueva. Nivel Cero 10, 113-128.

JEUNOT, L

2007 Les dépôts monétaires gaulois dans les grottes en Bourgogne orientale et Franche-Compté. L'Âge du Fer dans l'arc jurassien et ses marges. Dépôts, lieux et territorialité à l'Âge du Fer. Actes du colloque international de l'AFEAF, Bienne, 5-8 mai, 2005, vol 2, 493-498.

KAENEL, G. y CARRARD, F.

2007 La Baume du Four (Boudry, canton de Neuchâtel): un «Temple helvète»?. L'Âge du Fer dans l'arc jurassien et ses marges. Dépôts, lieux sacrés et territorialité à l'âge du Fer. Actes du XXIXe colloque international de l'AFEAF Bienne, 5-8 mai, 2005, vol 2, 499-536.

LEÓN, J.

1993 Antecedentes Históricos de las exploraciones de la cueva de la Coventosa. Boletín Cántabro de Espeleología, 9, 20-23.

1997 Cantabria subterránea: catálogo de grandes cavidades, tomo 1. Consejería de Cultura, Turismo y Deporte del Gobierno de Cantabria, Santander.

LLANOS, A.

1991 Dos nuevos yacimientos del horizonte Cogotas I en Álava. El depósito en hoyo de "El Pau" y cueva de Los Goros. Cuadernos de sección. Prehistoria y Arqueología 4, 219-238.

2003 De nuevo sobre el arte rupestre esquemático-abstracto en cuevas. Reflexiones sobre su cronología. Estudios de Arqueología Alavesa 20, 94-116.

LLANOS, A. y AGORRETA, J.A.

1962 La cueva sepulcral de Los Moros o de Peña Rasgada (Atauri, Álava). Noticiario Arqueológico Hispánico 6, cuadernos 1-3, 135-146.

\section{MARCOS MUÑOZ, J. L.}

1982 Carta arqueológica de Vizcaya: yacimientos en cueva Cuadernos de Arqueología de Deusto 8, Bilbao.

MARIËN, M. E.

1970 Le Trou de l'Ambre au Bois de Wérimont Eprave. Monographies d'Archéologie Nationale 4, Bruxelles.

MAYA, J. L.

1983 La cultura castreña asturiana: su etapa romano-provincial. Lancia 1, 221-262.

1988 La cultura material de los castros asturianos. Estudios de la Antigüedad 4/5, Barcelona.
1989 Los castros en Asturias. Silverio Cañada, Gijón.

1996 Cerámica de época celtibérica en la Edad del Hierro asturiana. Pyrenae 27, 287-294.

MOLINERO, J. T.

2000 Carta Arqueológica de Castro Urdiales (Cantabria). Paleolítico- Edad del Hierro. Ayuntamiento de Castro Urdiales.

MORLOTE, J. M.; SERNA, A.; MUÑOZ, E. y VALLE, M. A.

1996 Las cuevas sepulcrales de la Edad del Hierro en Cantabria. La Arqueología de los Cántabros. Actas de la Primera Reunión sobre la Edad del Hierro en Cantabria A.C.D.P.S. y C.A.E.A.P., Fundación Marcelino Botín, mayo 1995, Santander, 195-280

MUÑOZ, E.

1996 Los yacimientos en cueva de Cantabria. Boletín Cántabro de Espeleología 12, 90-104.

MUÑOZ, E. y MALPELO, B.

1992 Las cavidades sepulcrales de Cantabria. Actas del VI Congreso Español de Espeleología, La Coruña, 10,11 y 12 de Octubre, 287-308.

MUÑOZ, E. y RUIZ COBO, J.

2013 De Pesués a Pejanda: Arqueología de la Cuenca del Nansa (Cantabria, España). BAR International Series 2134, England.

MUÑOZ, E.; SERNA, A. y GÓMEZ AROZAMENA, J.

1992 Los materiales arqueológicos relacionables con las zonas de decoración en las cavidades con conjunto parietales esquemático-abstractos en Cantabria. Actas del VI Congreso Español de Espeleología, La Coruña, 10-11-12 de octubre de 1992, 309-322.

OLAETXEA, C.

2000 La tecnología cerámica en la Protohistoria Vasca. Munibe, suplemento 12, San Sebastián.

ORTEGA, A. I.

1999 Arqueología y Paleontología del Karst de Monte Santiago, Sierra Salvada y Sierra de la Carbonilla. Kaite 7, 243-281.

PEÑALVER, $X$.

2005 Orígenes. Txalaparta. Navarra.

PERALTA, E.

2003 Los cántabros antes de Roma. Real Academia de la Historia, Madrid.

PRADOS, L.

1994 Los santuarios ibéricos. Apuntes para el desarrollo de una arqueología del culto. Trabajos de Prehistoria 51, 127-140.

PUNCH, C

1998, Grandes cuevas y simas de España. Federación Española de Espeleología. Barcelona. 
PUJOL, J.; VERNHET, A. y VIDAL, M.

1998 Grottes-sanctuaires en Rouergue à la fin de la Protohistoire. Croyances et rites en Rouergue des origines á l'An mil, Musée Archéologique de Montrozie. Guide Archéologique 6, 127-162.

RAMALLO, B.

1997 El Santuario ibérico de la Encarnación. Quaderns de Prehistoria i Arqueologia de Castelló 18, 257-268.

\section{RASINES, P.}

1986-88 Algunos hallazgos antropológicos en cuevas de Cantabria. Sautuola 5, 19-46.

\section{RUIZ COBO, J.}

1996 La cerámica de la Edad del Hierro en el sector central de la Cornisa Cantábrica: aspectos tipológicos. La Arqueología de los Cántabros. Actas de la Primera Reunión sobre la Edad del Hierro en Cantabria, A.C.D.P.S. y C.A.E.A.P., Fundación Marcelino Botín, mayo 1995, Santander, 149-172.

2007 Paisaje y Arqueología en el Alto Asón (Cantabria, España). Resultados del proyecto de prospección arqueológica del Alto Asón. BAR International Series 1614, England.

2009 Los restos cerámicos en el contexto de las ocupaciones recientes de la cueva de Cobrante. Sautuola XV, 221-224.

\section{RUIZ COBO, J. y MUÑOZ, E.}

2009 La Prehistoria del Bajo Asón. Registro arqueológico e interpretación cultural (Cantabria, España. BAR International Series 1936, Oxford.

2013 El registro arqueológico del valle del Miera. BAR International Series 2542, Oxford

RUIZ COBO, J. y SMITH, P.

2001 The archaeology of the Matienzo Depression, North Spain. BAR International Series 975. Oxford.

2003 La cueva de Cofresnedo en el valle de Matienzo. Actuaciones arqueológicas 1996-2001. Gobierno de Cantabria, Santander.

RUIZ VÉLEZ, I.

2009 La cueva de Ojo Guareña (Burgos). El "príncipe" que se perdió y murió en ella. Sautuola XV, 261-274.

\section{RUIZ ZAPATERO, G. y LORRIO, A. J}

1995 La muerte en el norte peninsular durante el primer milenio a.C. Arqueología da Morte na Peninsula Ibérica desde as Orixes ata o Medievo, Actas do curso de Verán da Universidad de Vigo, 4 ó 8 xullo de 1994, 225-248.

\section{SAN MIGUEL, C.; MUÑOZ, E.; FERNÁNDEZ, V. y SERNA, A.}

1991 La cueva del Puyo (prospecciones arqueológicas destructivas en el año 84). Arquenas, 159-199.

SANZ, R.

2003 Paganos, adivinos y magos: análisis del cambio religiosos en la Hispania Tardoantigua. Anejos Gerión, Madrid.
SERNA, A

1992 Conclusiones previas a extraer del inventario de cavidades con yacimiento arqueológico en Cantabria. Actas del $\checkmark$ Congreso español de Espeleología, Camargo-Santander 1-4 noviembre, 256-267.

SERNA, A.; MALPELO, B.; MUÑOZ, E.; BOHIGAS, R.; SMITH, P. y GARCÍA ALONSO, M.

1994 La cueva del Aspio (Ruesga, Cantabria): avance al estudio del yacimiento. Museo y Centro de Investigación del Altamira, Monografías no 17, Homenaje al Dr. Joaquín González Echegaray, 369-396.

SERNA, A.; MUÑOZ, E.; VALLE, Mª.A; MORLOTE, J.M y SMITH, P. 1996 Las pinturas esquemático-abstractas: estado de la cuestión. La Arqueología de los Cántabros. Actas de la Primera Reunión sobre la Edad del Hierro en Cantabria A.C.D.P.S. y C.A.E.A.P., Fundación Marcelino Botín, mayo 1995, Santander, 281-294.

SMITH, P.

1985 Restos de la Edad del Hierro en Matienzo. Altamira 45, 45-66.

1996a El depósito arqueológico de la Cueva de los Reyes (Matienzo). La Arqueología de los Cántabros, Actas de la Primera Reunión sobre la Edad del Hierro en Cantabria, A.C.D.P.S. y C.A.E.A.P., Fundación Marcelino Botín, mayo 1995, Santander, 173-192.

1996b Sobre las técnicas y motivación de la realización de las marcas negras. La arqueología de los cántabros: Actas de la Primera Reunión sobre la Edad del Hierro en Cantabria, A.C.D.P.S. y C.A.E.A.P., Fundación Marcelino Botín, mayo 1995, Santander, 295-302.

SMITH, P. y MUÑOZ, E.

1984 La ocupación de las cuevas en la Edad del Hierro. Boletín Cántabro de Espeleología 4, 129-139.

2010 Las cuevas de la Edad del Hierro en Cantabria. A. Serna, A. Martínez y V. Fernández (coords.): Castros y Castra en Cantabria: fortificaciones desde los orígenes de la Edad del Hierro a las guerras contra Roma. Catálogo, revisión y puesta al día. ed. Acanto, Santander, 676-693.

SMITH, P.; RUIZ COBO, J. y CORRIN, J.

En prensa La cueva de Barandas (Matienzo, Cantabria): depósito y muerte. Sautuola 18.

SOPEÑA, G.

1987 Dioses, ética y ritos. Aproximaciones para una comprensión de la religiosidad entre los pueblos celtibéricos. Humanidades, Zaragoza.

TORRES-MARTÍNEZ, J. F.

2005 La economía de los celtas de la Hispania Atlántica: economía territorio y sociedad, vol II. Toxosoutos, A Coruña.

2010 Arqueología de la religión protohistórica en los pueblos del norte: el caso cántabro. A. Serna, A. Martínez y V. Fernández (coords.): Castros y Castra en Cantabria: fortificaciones desde los orígenes de la Edad del Hierro a las guerras contra Roma. Catálogo, revisión y puesta al día. ed. Acanto, Santander, 694-749.

2011 El Cantábrico en la Edad del Hierro: medioambiente, economía, territorio y sociedad. Real Academia de la Historia, Madrid. 
VALLE, M. A. y SERNA, A.

2003 El castro de Castilnegro y otros asentamientos de la Edad del Hierro en el entorno de la Bahía de Santander. C. Fernández lbañez y J. Ruiz Cobo (dir.) La Arqueología de la Bahía de Santander, 353-390.

VALLE, M. A.; HIERRO, J. A. y SERNA, A.

2005 Broches de cinturón hispanovisigodos y otros materiales tardoantiguos de la Cueva de las Penas (Mortera, Piélagos). Sautuola 11, 247-277

\section{VAN GENNEP, A}

2008 Los ritos de paso. Alianza, Madrid
VIDAL, M.; VERNHET, A. et PUJOL, J.

2000 Les grottes sanctuaires. À propos des exemples aveyronnais, première approche d'une étude comparative étendue au Sud de la France et à la Péninsule lbérique. Aspects de l'Âge du Fer dans le sud du Massif Central. Actes du Colloque International de l'AFEAF, ConquesMontrozier, 8-11 Mai 1997, 65-80.

WARMENBOL, E.

2007 Le dépôt d'ossements humains en grotte aux Âges des Métaux en Belgique. Nouvelles questions. L'Âge du Fer dans l'arc jurassien et ses marges. Dépôts, lieux sacrés et territorialité à l'âge du Fer. Actes du XXIXe colloque international de l'AFEAF, Bienne, 5-8 mai, 2005, vol 2, 537-548. 